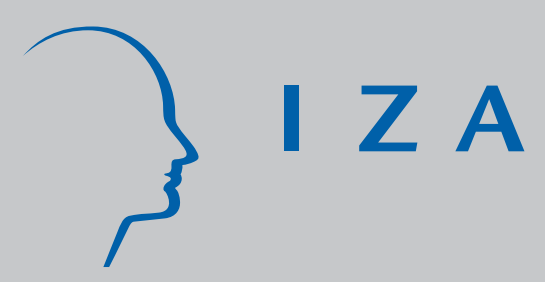

IZA DP No. 2854

Is the Notification of Monitoring a Threat to the Unemployed? A Regression Discontinuity Approach

Bart Cockx

Muriel Dejemeppe

J une 2007 


\title{
Is the Notification of Monitoring a Threat to the Unemployed? A Regression Discontinuity Approach
}

\author{
Bart Cockx \\ IRES, Université catholique de Louvain, \\ CESifo and IZA \\ Muriel Dejemeppe \\ IRES, Université catholique de Louvain
}

Discussion Paper No. 2854

June 2007

IZA

P.O. Box 7240

53072 Bonn

Germany

Phone: +49-228-3894-0

Fax: +49-228-3894-180

E-mail: iza@iza.org

Any opinions expressed here are those of the author(s) and not those of the institute. Research disseminated by IZA may include views on policy, but the institute itself takes no institutional policy positions.

The Institute for the Study of Labor (IZA) in Bonn is a local and virtual international research center and a place of communication between science, politics and business. IZA is an independent nonprofit company supported by Deutsche Post World Net. The center is associated with the University of Bonn and offers a stimulating research environment through its research networks, research support, and visitors and doctoral programs. IZA engages in (i) original and internationally competitive research in all fields of labor economics, (ii) development of policy concepts, and (iii) dissemination of research results and concepts to the interested public.

IZA Discussion Papers often represent preliminary work and are circulated to encourage discussion. Citation of such a paper should account for its provisional character. A revised version may be available directly from the author. 


\section{ABSTRACT}

\section{Is the Notification of Monitoring a Threat to the Unemployed? A Regression Discontinuity Approach*}

In July 2004, the Belgian government intensified monitoring within the Unemployment Insurance scheme. Workers claiming unemployment benefits for more than 13 months are notified that past job-search behavior will be monitored 8 months later. In one region the target group is counseled shortly after the notification, while in others not or only once the monitoring has taken place. We exploit the discontinuity in the treatment assignment at the age of 30 to evaluate the threat effect of the notification on the probability of employment. We find that the effect is heterogeneous and critically depends on whether and when notified workers are counseled.

JEL Classification: J64, J65, J68, H43

Keywords: evaluation, monitoring job-search, threat effect, regression-discontinuity

Corresponding author:

Muriel Dejemeppe

IRES

Université catholique de Louvain

Place Montesquieu 3

B-1348 Louvain-la-Neuve

Belgium

Email: dejemeppe@ires.ucl.ac.be

\footnotetext{
* This research has been assigned and financed by the Belgian federal administration of scientific research ("SPF Sciences") on request of the federal administration of employment ("SPF Emploi, Travail et Concertation sociale") within the program "Support for Strategic Priorities of the Federal Authority" (contract no. AP/10/04A). We acknowledge these institutions for their support. We are grateful to Anne Defourny and to Bruno van der Linden for the numerous discussions. We also thank Matteo Picchio, Michael Lechner and the participants of the COST conference in St. Gallen for their comments.
} 


\section{Introduction}

The Luxembourg European Council of November 1997 included active labor market policies as an essential ingredient of the Employment Guidelines set out for the member states of the European Union. By now it has become common knowledge that not all of these policies are equally effective in combating unemployment (see e.g. Martin and Grubb, 2001; Kluve, 2006). A number of studies have identified the monitoring of search behavior of the unemployed coupled with sanctions as a promising tool for enhancing the transition from unemployment to work(Meyer, 1995; Dolton and O'Neill, 1995, 1996; Gorter and Kalb, 1996; Blundell et al., 2004; Graversen and van Ours, 2006). Indeed, for risk averse workers, these policy instruments may deliver the right incentives by imposing less costs than alternatives, such as incomplete coverage or finite entitlement to unemployment benefits (Boone et al., 2001). However, since in these studies monitoring of search behavior was never offered in isolation of counseling, it is difficult to disentangle which policy drives the findings.

A number of recent studies challenge the view that monitoring of job search of unemployed workers is effective. ${ }^{1}$ First, Crépon et al. (2006) find that a number of intensive job search assistance programs in France without any threat of sanction accelerate the transition to employment and, in particular, delay the re-entry in unemployment. This proves that monitoring is not a necessary condition for success. Second, it is clear that employment officers can only verify formal proofs of job search behavior. van den Berg and van der Klaauw (2006) show that, as a consequence, monitoring may substitute informal by formal job search and that the total job search intensity among workers predominantly using informal search channels may even decline. Thirdly, Manning (2005) shows that the imposition of stricter job search requirements does not enhance search incentives for all workers, since, if behavior is followed-up too closely, workers may find it too onerous to continue claiming benefits. As a consequence, these workers leave the claimant population and search less intensively. Finally, Klepinger et al. $(1997,2002)$ report the outcomes of a social experiment especially designed to evaluate the effect of alternative work-search requirements within Unemployment Insurance (UI) in the United States. This study confirms that monitoring may reduce the duration of benefit claim, ${ }^{2}$ but that it neither speeds up the transition to employment nor has any impact on the level of subsequent earnings.

\footnotetext{
${ }^{1}$ This does not imply that the sanction associated to the monitoring isn't effective (see e.g. Abbring et al., 2005; van den Berg and van der Klaauw, 2005).

${ }^{2}$ Ashenfelter et al. (2005) find insignificant effects, but Klepinger et al. (2002, p.19) claim that the discrepancy with their conclusions is essentially caused by the smaller sample size of Ashenfelter et al.'s study, resulting in less precision.
} 
Even if the monitoring activity as such does not promote the transition from unemployment to work, the threat of monitoring may do. Indeed, if unemployed workers dislike being monitored, they will try to avoid it by searching harder for jobs before the employment officers start following-up their behavior. If so, we should regard this anticipatory effect as an integral part of the treatment effect of monitoring. In this paper we examine whether the new follow-up scheme enacted by the Belgian government in July 2004 entails important effects of this kind.

The threat effect of unemployment benefit exhaustion has been extensively studied in the literature (see e.g. van den Berg, 1990; Fredriksson and Holmlund, 2006). This literature provides convincing evidence that incentives to search for and to accept jobs increases significantly as unemployed workers approach the moment at which benefits expire. Only recently researchers have started to investigate whether the prospect of mandatory participation to active labor market policies have a similar impact on the behavior of unemployed workers (Black et al., 2003; Rosholm and Svarer, 2004; Geerdsen, 2006; Geerdsen and Holm, 2007; Graversen and van Ours, 2006; Forslund and Nordström Skans, 2006; Hägglund, 2006). They have shown that these threat effects can be as large as those resulting from a finite entitlement of unemployment benefits and that they may form a major share of the total impact on the return to employment. A major concern remains, however. The threat of participation may accelerate the transition to work at the expense of the quality of the job. van Ours and Vodopivec (2006) report that shortening the potential duration of unemployment benefits in Slovenia did not affect the contract type (temporary versus permanent), neither the employment duration nor the wage of the post-unemployment job. In this study we only have very partial information regarding the quality of the job. Nevertheless, we find some evidence that the threat of monitoring induces workers to accept lower quality jobs, but that this negative effect can be undone if these workers are appropriately counseled.

We estimate the impact of the threat of monitoring on the probability of employment on the basis of a regression-discontinuity (RD) analysis (Campbell, 1969; Hahn et al., 2001). This approach is appealing, since it allows, as in an experimental setting, to identify the treatment effect under very weak assumptions. We can follow this approach, because the Belgian government phased in the monitoring scheme gradually according to age group. Between June 2004 and June 2005 only unemployed workers younger than 30 years were obliged to participate in the new scheme. In this study we analyze the effect of the new scheme during this initial phase. This means that we exploit the discontinuity in the treatment assignment at the age of 30 .

The outline of the article is as follows. In the next section we describe the institutional set- 
ting and the features of the new monitoring scheme. In Section 3 we discuss the sample selection criteria and provide descriptive statistics of the data. Section 4 presents the estimation method. Section 5 reports the main findings for the benchmark model and relates them to the predictions of a theoretical model developed in the Appendix. Section 6 considers some robustness checks and extends the analysis to other outcome variables. A final section concludes.

\section{Institutional Setting}

Belgium is a federal state consisting of three language Communities (the French, the Flemish and a small German one) and of three Regions (Flanders, Wallonia and Brussels). In Flanders the official language is Dutch (Flemish), in Wallonia it is French and the large majority of the inhabitants of Brussels speak French, a minority Dutch or other languages. ${ }^{3}$ Flanders is currently the most prosperous region. In 2004, the ILO-unemployment rate was $5.4 \%$ on average in Flanders, where it was as high as $12.0 \%$ in Wallonia and 15.7\% in Brussels (Massant, 2005).

Within this institutional setting, Social Insurance, of which Unemployment Insurance (UI) is one division, is organized at the federal level. The Public Employment Services (PES) are Regional institutions. They provide various forms of assistance (counseling, various types of training and other activation measures) to unemployed workers as well as intermediation services to firms, and to unemployed and employed workers.

The new monitoring and counseling scheme introduced by the Belgian government in July 2004 induced a major reform within (i) UI and (ii) the assistance for unemployed persons offered by the Regional PES. We will review these two changes in turn.

\subsection{Unemployment Insurance}

\subsubsection{General Features}

On the one hand, the UI system in Belgium is quite generous and unique in the world in that it entitles unemployed individuals to benefits for an, in principle, unlimited period and also to school-leavers without any work history after a waiting period of 9 months. ${ }^{4}$ On the other, incentives to work are preserved by a relatively low gross replacement rate. In principle, the replacement rate, as a percentage of gross wage, of a worker with a sufficient employment record is not higher than $55 \%$ or $60 \%$, depending on whether or not the worker cohabits with

\footnotetext{
${ }^{3}$ Due to the presence of the institutions of the European Union and other international organizations, there are many foreigners living in Brussels.

${ }^{4}$ This waiting period lasts only 6 months for those aged less than 18 years and 12 months for youth between 26 and 30. See www.onem.be for more information.
} 
a person earning (replacement) labor income. For low-wage workers it may be higher, since the allowance may not drop below some minimum level depending on the household type, but it is never higher than $73 \% .^{5}$ The replacement rate is, however, generally lower than $55 \%$ or $60 \%$ : (i) the level of the allowance is capped if past labor earnings exceed a maximum (1778€ / month in October 2006), so that the replacement rate falls as earnings increase above this threshold; (ii) the allowance remains indefinitely at the same level only for a head of a household; for singles and cohabitants the replacement rate drops to respectively $50 \%$ and $40 \%$ after a year and three months later the benefit level of cohabitants decreases further to a flat rate of $405 € /$ month; $^{6}$ (iii) school-leavers are entitled to flat rate benefits ranging between $27 \%$ and $71 \%$ of the federal minimum wage, ${ }^{7}$ respectively for a cohabitant and a head of a household. In 2005, roughly one quarter of the claimants were entitled to benefits as school-leaver. Among these persons 35\% were head of household and 44\% cohabiting (RVA, 2006b).

Usually, the average gross replacement rate in Belgium is ranked relatively high in international statistics. In 2003, e.g., it is reported to be $42 \%$ compared to $34 \%$, on average, in the four neighboring countries (France, Germany, The Netherlands and the UK). ${ }^{8}$ However, these figures are biased since they ignore that in the other countries the unemployed may be entitled to social assistance after benefits exhaust. If one takes this into account (as well as the tax system), the average net replacement rate in Belgium is $68 \%$, well below the $73 \%$ average in the neighboring countries. ${ }^{9}$

\subsubsection{Monitoring and sanctions}

Before July 2004, the benefits could be withdrawn for two main reasons. First, Article 80 of the UI legislation imposed a finite entitlement to UI for cohabitants whose household income was not too low (Cockx and Ries, 2004). Depending on the sub-region of residence, the gender and the age-class, the duration at which exhaustion occurred varied between 24 and 99 months. Since the large majority of cohabitants are women, the scheme has been criticized for being implicitly discriminatory. This was the main reason why the Belgian government decided to abolish Article 80 at the same pace as the new monitoring scheme was phased in,

\footnotetext{
${ }^{5}$ This rate is attained for a minimum wage worker who is a head of household in charge of dependents without any (replacement) labor income.

${ }^{6}$ If the income of the cohabiting person consists of allowances only and does not exceed $712 € /$ month, then one is entitled to $531 € /$ month.

${ }^{7}$ In October 2006 this minimum was set at 1,259€/month for someone aged 21 or more and at 1,032€/month for an 18 year old person. The replacement rate mentioned in the text applies to workers aged 21 years or more. Note, since in most sectors trade unions have bargained higher minimum wages, only a small fraction of the workers are paid the federal minimum.

${ }^{8}$ See www.oecd.org/els/social/workincentives (Table on gross replacement rates 1961-2003).

${ }^{9}$ See www.oecd.org/els/social/workincentives (Table on net replacement rates during a 5-year period following unemployment, 2001-2004).
} 
i.e. gradually according to age-group.

Second, sanctions lead to a temporary or permanent benefit withdrawal. These sanctions are essentially imposed if the claimant is detected to have made a false declaration (e.g. with regards the household type or an undeclared employment relationship) or to be unavailable for the labor market (not registered as a job searcher at the Regional PES, not turning up at a convocation of this office, refusing a "suitable" job offer or refusing participation in an activation or training program, etc.). Before the reform in 2004, roughly $80 \%$ of the monitoring reports regarding availability concerned not turning up to a convocation (RVA, 2006a, pp. 72).

In Belgium the Regional PES (VDAB in Flanders, FOREM in Wallonia and ORBEM/BGDA in Brussels) are in charge of verifying whether workers are available for the labor market, whereas the sanctioning is the competence of the federal Unemployment Agency (UA). Consequently, the effectiveness of monitoring crucially depends on the transmission of information from the regional PES to the federal agency. Before 2004, this information transmission did not occur very systematically and was based on paper files. Moreover, the Walloon PES were not very collaborative and transmitted hardly any information, this in contrast to Flanders and to Brussels.

\subsubsection{The reform of the monitoring scheme in 2004}

In July 2004, the federal government chose to replace Article 80 with a new, fairer system which could, at the same time, guarantee the viability of an UI system in which benefits do not expire. Two main features characterize the new system.

First, the new cooperation agreement reached on April 30, 2004 between the Federal State, the Communities and the Regions resulted in a much more systematic and electronic exchange of data with regards the availability for the labor market between the Regional PES and the federal UA. This exchange is operational since October 2004, but it is only since the second semester of 2005 that one observes a notable increase in information flows, especially in Wallonia (RVA, 2006a, pp. 72-75).

Second and more importantly, the reform assigns to the federal UA the competence to monitor, within a number of interviews, the effort that claimants devote to job search. Consequently, the capacity of the agency to sanction workers for being unavailable for the labor market no longer depends exclusively on the information transmitted by the Regional PES. This monitoring occurs within the so called "procedure for the Activation of Job Search Behavior" (AJSB). Within this procedure the federal Unemployment Agency dispatches a no- 
tification letter, restating the obligations of unemployed benefit claimants with regards job search and labor market availability, and explaining the different steps of the AJSB. This occurs at an unemployment duration of 7 months for those under the age of 25 and at 13 months for those older than 25 (the "flow"). In addition, individuals who, in July 2004, had been claiming benefits during more than 7 or 13 months (the "stock") were addressed as well.

Eight months after sending the notification letter, the UA starts convoking the unemployed to a meeting with a caseworker. ${ }^{10}$ In this meeting the caseworker evaluates, on the basis of proofs delivered by the unemployed worker (copies of letters of application, registration in temporary help agencies, proofs of participation to selection procedures, etc.), whether the claimant has been actively searching for work during the last 12 months. If the outcome of this evaluation is positive, the worker will not be monitored during the next 16 months. If not, the worker must sign an action plan and is invited to a new meeting 4 months later. Sanctions are imposed on workers not showing up without justification at the meeting or not complying with the action plan. These sanctions consist in a temporary or permanent withdrawal of benefits. In the latter case the worker can regain entitlement only after proof of a sufficient employment record..$^{11}$

To cope with capacity problems, the new program was gradually phased in according to age. In the first year, only workers younger than 30 years were contacted and the notification of the "stock" was spread out over the year according to age, starting with the youngest claimants. In the second year, starting in July 2005, the target group was enlarged to those younger than 40 and, in the third year, those between 40 and 50 years old were included. Claimants older than 50 are not concerned by the ASJB.

The gradual phasing-in resulted during the first years in discontinuous relationships between the age and the program participation. We exploit these discontinuities to identify the threat effects induced by the above-mentioned letter of notification (see Section 4). However, it's important to realize that these discontinuities only apply to the "flow" and not to the "stock": for the latter group the timing of the treatment evolves gradually with age within each age-group canceling thereby the potential discontinuity between age groups. This is unfortunate, since it reduces the sample size (see Section 3).

\footnotetext{
${ }^{10}$ The procedure can be deferred if the claimant participates or has participated in an assistance program of one of the Regional PES (for further details, see Cockx et al., 2007).

${ }^{11}$ A worker can regain entitlement to benefits by working at least 312 days, full-time (or part-time), within the 18 (24) months preceding the new application.
} 


\subsection{Assistance}

The reform in July 2004 did not only reinforce the "stick", it also enhanced the "carrot". Indeed, the Regional PES significantly increased their assistance to unemployed workers. In all three regions, the supply of counseling and training programs has risen importantly (Cockx et al., 2007, pp. 26-52). In addition, the reform was seized as an opportunity to move closer to the recommendations described in the first European guideline for employment. This recommends, on the one hand, a preventive approach aimed at activating all unemployed persons at an early stage in their period of unemployment and, on the other hand, a curative approach aimed at systematically directing the long-term unemployed towards appropriate actions that promote their re-employment. Before 2004, the Walloon and Brussels' Regional PES offered a preventive approach to low-skilled youth only. In contrast, the Flemish PES introduced the preventive approach already in 1999 and this for all unemployed job-seekers. Since 2004, Wallonia and Brussels expanded the preventive approach to adults and all three Regional PES introduced a curative approach, previously non-existent.

Since 2004, the assistance provided to unemployed workers is structured in a similar way in the three regions. It starts with an individual intake meeting with a caseworker in which a mandatory action plan is proposed. The action plan may (but need not) consist in the participation in (a sequence of) counseling and/or training programs. Participation in the plan is mandatory and refusal is notified to the federal UA that may impose a sanction on this basis. The curative approach differs from the preventive one in that a collective information meeting precedes the individual intake.

Regional differences concern the timing of the intervention. We focus on the curative approach, since this is the one that matters in the empirical analysis. In Wallonia, the unemployed are convoked to the first collective information meeting within two months after dispatch of the notification letter within the above-mentioned AJSB procedure, i.e. after 7 and 13 months of unemployment respectively for individuals younger and older than 25 years. The new assistance scheme was phased-in according to age-groups at exactly the same pace as the above-mentioned AJSB procedure. This means that until June 2005 only those below the age of 30 participated. It implies that the RD design used in this research identifies for Wallonia not only the impact of the threat effect of the notification letter within the ASJB procedure, but also the participation in the Regional counseling scheme.

In Brussels the unemployed are invited to a collective information session at the same moment as in Wallonia. However, in contrast to Wallonia, it is announced to participants that they are convoked to the individual intake with the caseworker after the first monitoring interview within the AJSB procedure. As we will explain more in detail in Section 5, this 
announcement could reduce, cancel or even reverse the threat effect of the monitoring, since the benefit claimant may temporarily reduce his job-search effort as to benefit from the action plan he will be entitled to if he is still unemployed. If so, this should be uncovered in the empirical analysis, since the phasing-in of the curative approach occurred completely parallel to that of the new federal monitoring scheme.

Finally, in Flanders, the first collective meeting takes place close to the moment at which the first interview within the AJSB procedure takes place, i.e. after 15 and 21 months, respectively for youth aged less than 25 years and older individuals. However, it is only offered to unemployed workers who did not receive any counseling in the preceding two years. Consequently, it concerns only a small group of workers that for some reason was not attained by the preventive approach. Moreover, since the curative approach was introduced in Flanders at a faster pace than the ASJB procedure, already in 2004 it concerned workers between the age of 30 and 40 . This means that in Flanders the contrast between workers aged slightly less

and more than 30 years can only reveal the impact of the notification within the monitoring procedure and not the impact of the enhanced counseling.

\section{The Data}

The analysis is based on monthly administrative reports of the federal UA on benefit claims. We neither have any information on the assistance provided by the Regional PES nor on the reason why benefit claims end. Nevertheless, we will argue below that the measured effect of the notification letter on the probability of not being a claimant, reflects the effect on the probability of being employed. We first justify the sample selection criteria and the choice of the observation period. Subsequently, we provide descriptive statistics of the retained sample. Finally, we discuss the choice of the outcome variables retained in the evaluation.

\subsection{Sample selection criteria and choice of the observation period}

The empirical analysis exploits the age-discontinuity in the assignment to treatment between the $1^{\text {st }}$ of July 2004 and the $30^{\text {th }}$ of June 2005: in that period only claimants of UI less than 30 years old were notified of the AJSB procedure. The fact that individuals older than 30 years are only temporarily dispensed of treatment complicates the analysis. First, it limits the period over which the treatment effect can be measured to maximum one year. This means that claimants unemployed for more than 13 months on the $1^{\text {st }}$ of July 2004 (the "stock") could not be retained in the sample: individuals in this group slightly younger than 30 years are notified close to the moment at which the slightly older ones are (see Section 2.1). Second, the unemployed older than 30 could anticipate their treatment within a year. They would then be invalid controls to the treatment. However, in the robustness analysis below we will 
demonstrate that this anticipation, if it occurs, cannot be very important.

The sample contains claimants of unemployment benefits, who on the $1^{\text {st }}$ of July 2004 were between 25 and 34 years old and who satisfy all the criteria ${ }^{12}$ (except for the age, if older than 30) to be dispatched a notification letter between July and October 2004. Since reliable data on benefit payments are only available with some delay, the claimant status and duration criterion (13 months) is determined on the basis of payments made two to three months before the (theoretical) moment of dispatch of the notification. This delay implies that a number of workers are no longer claiming benefits at the moment that they (should) receive the notification. Since we focus in this research on the threat effect of the letter on unemployed benefit claimants, we drop these non-claimants from the sample. ${ }^{13}$

To select the unemployed older than 30 years according to exactly the same rules as the younger ones, we asked the federal UA to run ex post (in April 2006) the computer program that identifies the population to be notified. Nevertheless, since the program is run ex post, it does not select exactly the same population as the one that would have been if the older group were to be notified between July and October 2004: due to administrative mistakes and to appeals to decisions of benefit withdrawal, some data regarding payments are corrected ex post. In addition, the initial selection program contained some bugs that have been corrected meanwhile. This problem shows up if we compare the population younger than 30 years that effectively received a notification letter in a particular month with the one that should have according to the ex post simulation. Roughly $15 \%$ of the simulated population are not notified in the month that they should have been according to the simulation. The majority is, however, notified the next month.

To avoid sample selection, we select the population younger than 30 years old in exactly the same way as the untreated older workers. A consequence of this choice is that the "sharp" RD design turns into a "fuzzy" one (Hahn et al., 2001): only a fraction (95\% on average) of the sampled workers below the age of 30 years has effectively been treated. In the next section we discuss the methodological implications.

In the empirical analysis we estimate the impact of the notification on a number of outcome variables up to eight months after dispatch of the letter. We choose not to extend the analysis beyond eight months for two reasons. First, the focus of this research is on the threat effect of the notification (possibly combined with counseling). Since from the $9^{\text {th }}$ month onwards,

\footnotetext{
${ }^{12}$ Aside from being unemployed more than 13 months, there exist a number of additional criteria that we ignore for the sake of not overloading the reader with details.

${ }^{13}$ This reduces the size of the sample by $16 \%$ on average, by $12 \%$ in Brussels and Wallonia and by $20 \%$ in Flanders. The higher fraction in Flanders reflects the better condition of the labor market in that Region.
} 
Table 1: Descriptive Statistics by Region of Living and Age Group

\begin{tabular}{|c|c|c|c|c|c|c|}
\hline & \multicolumn{2}{|c|}{ Brussels } & \multicolumn{2}{|c|}{ Flanders } & \multicolumn{2}{|c|}{ Wallonia } \\
\hline & 25-29 years & 30-34 years & $25-29$ years & 30-34 years & 25-29 years & 30-34 years \\
\hline Number of individuals & 758 & 588 & 1,341 & 1,178 & 1,331 & 1,082 \\
\hline \multicolumn{7}{|l|}{ Month of (potential) notification } \\
\hline July & $27.0 \%$ & $27.4 \%$ & $28.9 \%$ & $29.4 \%$ & $28.0 \%$ & $29.5 \%$ \\
\hline August & $25.5 \%$ & $28.1 \%$ & $25.1 \%$ & $23.9 \%$ & $20.5 \%$ & $22.2 \%$ \\
\hline October & $24.3 \%$ & $21.6 \%$ & $22.5 \%$ & $24.3 \%$ & $23.5 \%$ & $25.9 \%$ \\
\hline November & $23.2 \%$ & $23.0 \%$ & $23.6 \%$ & $22.5 \%$ & $28.0 \%$ & $22.5 \%$ \\
\hline \multicolumn{7}{|l|}{ Age } \\
\hline $\begin{array}{l}\text { mean age in years on July 1, } 2004 \\
\text { (standard deviation) }\end{array}$ & $\begin{array}{l}27.0 \\
(1.4)\end{array}$ & $\begin{array}{l}32.0 \\
(1.4)\end{array}$ & $\begin{array}{l}26.9 \\
(1.4)\end{array}$ & $\begin{array}{l}32.0 \\
(1.4)\end{array}$ & $\begin{array}{l}26.8 \\
(1.4)\end{array}$ & $\begin{array}{l}32.0 \\
(1.4)\end{array}$ \\
\hline \multicolumn{7}{|l|}{ Sex } \\
\hline $\begin{array}{l}\text { women } \\
\text { Nationality }\end{array}$ & $48.8 \%$ & $44.1 \%$ & $52.1 \%$ & $53.0 \%$ & $45.9 \%$ & $46.1 \%$ \\
\hline Belgian & $75.2 \%$ & $65.5 \%$ & $90.2 \%$ & $86.8 \%$ & $90.4 \%$ & $85.5 \%$ \\
\hline EU15 (excluding Belgian) & $11.1 \%$ & $14.0 \%$ & $2.8 \%$ & $5.0 \%$ & $7.3 \%$ & $10.1 \%$ \\
\hline Others & $13.7 \%$ & $20.6 \%$ & $6.9 \%$ & $8.2 \%$ & $2.3 \%$ & $4.4 \%$ \\
\hline \multicolumn{7}{|l|}{ Schooling level } \\
\hline primary & $11.0 \%$ & $17.0 \%$ & $14.6 \%$ & $22.3 \%$ & $13.8 \%$ & $20.5 \%$ \\
\hline lower secondary & $15.4 \%$ & $13.8 \%$ & $19.5 \%$ & $17.7 \%$ & $19.3 \%$ & $21.4 \%$ \\
\hline upper secondary & $36.4 \%$ & $25.5 \%$ & $45.0 \%$ & $41.9 \%$ & $41.5 \%$ & $35.2 \%$ \\
\hline higher education & $21.1 \%$ & $17.0 \%$ & $20.8 \%$ & $17.7 \%$ & $22.8 \%$ & $15.0 \%$ \\
\hline other studies & $16.1 \%$ & $26.7 \%$ & $0.1 \%$ & $0.3 \%$ & $2.6 \%$ & $7.9 \%$ \\
\hline \multicolumn{7}{|l|}{ Category of unemployed worker ${ }^{(a)}$} \\
\hline head of household & $22.6 \%$ & $28.7 \%$ & $15.0 \%$ & $23.6 \%$ & $19.2 \%$ & $25.8 \%$ \\
\hline single & $37.7 \%$ & $36.9 \%$ & $24.1 \%$ & $23.0 \%$ & $27.4 \%$ & $23.8 \%$ \\
\hline cohabitant & $39.7 \%$ & $34.4 \%$ & $60.9 \%$ & $53.4 \%$ & $53.3 \%$ & $50.4 \%$ \\
\hline \multicolumn{7}{|l|}{ Type of entitlement to benefits ${ }^{(a)}$} \\
\hline work experience & $79.0 \%$ & $99.3 \%$ & $82.6 \%$ & $98.9 \%$ & $74.2 \%$ & $98.0 \%$ \\
\hline school-leaver & $21.0 \%$ & $0.7 \%$ & $17.5 \%$ & $1.1 \%$ & $25.8 \%$ & $2.0 \%$ \\
\hline Participation in training ${ }^{(a)(b)}$ & $5.4 \%$ & $5.1 \%$ & $9.3 \%$ & $8.5 \%$ & $6.9 \%$ & $7.3 \%$ \\
\hline Unemployment duration & 14.3 & 14.7 & 13.7 & 14.4 & 13.7 & 14.5 \\
\hline in months ${ }^{(\mathrm{a})(\mathrm{c})}$ (standard deviation) & $(5.8)$ & (6.9) & (6.4) & $(7.0)$ & $(6.2)$ & (5.9) \\
\hline Recent UI interruption $^{(a)(d)}$ & $32.7 \%$ & $38.9 \%$ & $26.9 \%$ & $33.3 \%$ & $27.6 \%$ & $33.1 \%$ \\
\hline Unemployment rate ${ }^{(\mathrm{e})}$ by district & $22.3 \%$ & $22.3 \%$ & $8.4 \%$ & $8.3 \%$ & $22.1 \%$ & $21.4 \%$ \\
\hline of living (standard deviation) & - & - & $(1.8)$ & (1.8) & $(5.2)$ & $(5.4)$ \\
\hline
\end{tabular}

(a) At the sample selection date, 2-3 months before the (potential) dispatch of the notification.

(b) During the 13 months-period prior to the sample selection date.

(c) According to the Eurostat definition: counts the number of months that unemployment benefits are claimed counting one month independently of number of days claimed and setting the duration counter to zero only after an interruption of more than three months.

(d) This indicator is equal to one if, during the 13 months preceding the sample selection date, one stopped claiming benefits during more than 1 months, but less than 3 months and zero otherwise.

(e) The number of benefit claimants available for the labor market divided by the number of workers insured against unemployment, by sub-region on June 30, 2004 (ONEM, 2004, p.65).

some notified individuals pass their first interview with the caseworker of the UA, the treatment is no longer homogenous beyond the $8^{\text {th }}$ month. Second, the workers older than 30 who are sampled in October 2004 start to be notified themselves as from July 2005, i.e. 9 months later. They are therefore no longer a valid control as from that moment.

\subsection{Descriptive statistics}

Table 1 reports descriptive statistics of the sampled population and this separately for the three Regions (Flanders, Wallonia and Brussels). For each of these Regions, the first column refers to the sample of unemployed workers between 25 and 29 years old and the second to those aged between 30 and 34. First observe that, in spite of having population data, the 
sampled population is not very large: roughly 2,500 individuals in Flanders and Wallonia and 1,300 in Brussels. The reason is that we could not include the stock sample of individuals with an unemployment duration of more than 13 months (see Sections 3.1 and 2.1). The sample of the older workers is slightly smaller $(2,848)$ than the younger one $(3,430)$.

For each of the above-mentioned groups Table 1 reports information with respect to a number of observed characteristics of the unemployed workers: the starting date of the observation window (July, August, September or October 2004), the age reported in years (but measured in months) on the $1^{\text {st }}$ of July 2004, the gender, the nationality, the level of education, the household-type determining the benefit level (head of household, single or cohabitant), the type of entitlement (school-leaver or work experience), an indicator of participation in training during the 13-month period prior to the sample selection date, the elapsed unemployment duration according to the Eurostat definition, an indicator of recent interruption of UI during more than one and less than three months, the unemployment rate by district of living. For the continuous variables, we report the average and the standard deviation, for discrete variables the average proportions. Time-varying variables are evaluated at the sampling date, i.e. two or three months prior to the (potential) dispatch of the notification letter.

The reader may question why the unemployment duration is not equal to 13 months for all sampled individuals. The reason is that the unemployment duration as measured according to the Eurostat definition - common in official statistics of unemployment duration - does not match the one that is used within the AJSB procedure. The latter is obtained by dividing the number of days that the worker claimed unemployment benefits into 26 and rounding down to the nearest integer. The duration counter is reset to zero if the worker has been 12 months full time employed within the preceding 15 months. In contrast, the Eurostat duration rounds up to the nearest month even if the unemployed worker claimed benefits during just one day. The duration counter is reset to zero if the worker did not claim any benefits during three consecutive months. ${ }^{14}$ Consequently, the Eurostat duration can be larger or smaller than 13. If it's smaller than 13 months, the worker must have interrupted unemployment at least once during more than 3 months (without being full time employed for more than one year); the larger it is, the less likely such longer interruptions occurred recently. The Eurostat duration can therefore be considered as a proxy for the employability of the worker: the smaller it is, the more likely the worker recently had some significant ${ }^{15}$ work experience.

The indicator of recent interruption of UI can be regarded as an additional indicator of labor

\footnotetext{
${ }^{14}$ See Cockx et al. (2007, p.19) for more details.

${ }^{15}$ More than 3 months.
} 
market attachment. This indicator is equal to one if, during the 13 months preceding the sample selection date, one stopped claiming benefits during more than 1 month, but less than 3, and zero otherwise. We add this variable, since it identifies benefit claimants with a recent labor market experience for whom the Eurostat unemployment duration may be quite long, since this duration is only reset to zero if the interruption lasts more than 3 months. The econometric analysis revealed that the inclusion of this indicator is crucial for the analysis of impact heterogeneity.

On the basis of Table 1 we can deduce that the composition of the populations varies across both, Regions and age groups. This is not surprising, since the observed characteristics are often correlated with the region or the age. In Brussels, e.g., the fraction of foreigners is known to be higher than in the two other regions. Younger workers are in general more educated and are more likely to be entitled to benefits as a school-leaver, since the probability of recently completing education and working is obviously respectively higher and lower than that for older workers. The correlation of the observed characteristics with age is not problematic, as long as there is no discontinuity at the age of 30 (see Section 6.3).

\subsection{The outcome variables}

The benchmark outcome is an indicator variable measured each month between the month of dispatch of the notification and eight months later. It is equal to one if one of the two following conditions is satisfied: within the considered month the worker (i) does not claim any unemployment benefits or (ii) he claims benefits (at least during one day) while he occupies a job. It is equal to zero otherwise.

Workers may remain entitled to benefits even if they are employed. The following two situations are the most common ones: ${ }^{16}$ (i) Part-time workers in search of full-time employment are eligible to an income supplement if they earn not too high a wage; (ii) Under certain conditions hired workers temporarily continue claiming benefits under the form of a wage subsidy, the so called "work allowance". These two outcomes represent, on average, $11 \%$ of the instances in which the benchmark outcome is equal to one. In Section 6 we will consider the receipt of an income supplement in part-time jobs as a separate outcome.

The benchmark outcome is not only zero for unemployed workers: a benefit claimant may under some conditions be temporarily dispensed from job search if he or she participates in training or in full-time education, or if he or she faces particular social or family problems, e.g. raising children below the age of four. Neither of these two situations, nor the "work allowance" is considered as separate outcome in this article. The interested reader is referred

\footnotetext{
${ }^{16}$ Other cases are enumerated in Cockx et al. $(2007$, p.86).
} 
to Cockx et al. (2007).

As higher mentioned, the benchmark indicator is not only equal to one if one has returned to work: one can continue search without benefits or withdraw from the labor force. We argue, however, that, as long as the first interview of the AJSB procedure did not take place, the variation of the benchmark indicator induced by the notification letter and by the specific assistance provided to the unemployed in Wallonia and Brussels, should reflect the causal effect on employment. Let us briefly explain why. In the period between the notification and the first interview, the behavior of claimants is not monitored more intensively. ${ }^{17}$ There exists only the threat of monitoring. Consequently, there is no reason to give up benefits in this period unless the unemployed person can be better off by doing so. It is difficult to imagine that this would occur in other situations than being offered a higher paying job.

The empirical analysis reported in Cockx et al. (2007) supports this interpretation of the benchmark indicator. First, we find that the treatment did not affect in any Region the number of sanctions imposed on the unemployed during eight months following the notification. This is consistent with the hypothesis that monitoring did not increase before the first interview. Second, during the observation period, we neither find any significant increase of exemptions due to social and family reasons, consistent with the hypothesis that there shouldn't be any effect on the withdrawal rate from the labor force. In the sequel we therefore refer to "employment" as the benchmark outcome.

Critics allege that monitoring schemes may increase employment, but also reduce the quality of the accepted job offers: workers accept low wage, part-time and unstable employment to avoid the burden imposed by the monitoring and the risk of a sanction. In Section 6 we try to obtain more insight in this issue by estimating the impact of the treatment on a number of additional outcomes. First, we investigate the effect of the notification on the stability of the employment relationship by considering the following two outcome variables: the probability of leaving remunerated unemployment during more than 3 and 6 months. Second, we evaluate whether the treatment affects the transition rate to the higher mentioned low wage part-time work in which an income supplement is due.

\footnotetext{
${ }^{17}$ The Walloon PES convokes the notified unemployed workers to an intake interview and proposes an individual action plan, but until the second semester of 2005 (beyond the observation period of the empirical analysis) the Office did not transmit refusals to participate to the federal UA so that no sanction was pending. We argue in Section 5 that the PES of Brussels may even have signalled to the recipients of the notification that the unemployed are monitored less until the first interview.
} 


\section{The Econometric Model}

Consider $Y_{i t c}$ the observed outcome for individual $i$ evaluated $t$ months after dispatch of the notification at calendar time $c{ }^{18} Y_{i t c}^{1}$ and $Y_{i t c}^{0}$ denote the outcome respectively in case of notification or not. If $D_{i t c}$ denotes the binary treatment indicator equal to one if at calendar time $c$ individual $i$ has been notified $t$ months earlier and zero otherwise, then the model of the observed outcome can be written as follows:

$$
Y_{i t c}=\beta_{t c}+\alpha_{i t c} D_{i t c}+u_{i t c}
$$

where $Y_{i t c}^{0} \equiv \beta_{t c}+u_{i t c}, \alpha_{i t c} \equiv Y_{i t c}^{1}-Y_{i t c}^{0}$ and $E\left(u_{i t c}\right)=0$. Even if the treatment effect is constant in the population $\left(\alpha_{i t c}=\bar{\alpha}_{t c}\right)$, in general $E\left(u_{i t c} \mid D_{i t c}\right) \neq 0$, so that an OLS estimate of $\bar{\alpha}_{t c}$ would be inconsistent. However, since the probability of treatment depends discontinuously on age at 30 years, a two-stage least squares procedure consistently estimates the average treatment effect locally at that age (Hahn et al., 2001; van der Klaauw, 2002; Wooldridge, 1997).

To see this, first recall that we have to do with a fuzzy RD design (cf. Section 3.1), since the assignment to treatment is stochastically and discontinuously related to the running variable, i.e. the age $A_{i}$ of individual $i$ on the 1 st of July $2004:^{19}$

$$
E\left(D_{i t c} \mid A\right)=P\left(D_{i t c} \mid A\right)=f_{t c}(A) 1\{A<30\}
$$

where $1\{$.$\} is the indicator function and f_{t c}($.$) is some continuous function of A$. If we denote $E\left(u_{i t c} \mid A_{i}=a\right) \equiv k_{0 t c}(a), E\left(\alpha_{i t c} \mid A_{i}=a\right) \equiv \alpha_{t c}(a)$ and $\left[\alpha_{t c}(a)-\alpha_{t c}(30)\right] f_{t c}(a) \equiv k_{1 t c}(a)$, we can rewrite the regression equation (1) in the following way:

$$
Y_{i t c}=\beta_{t c}+\alpha_{t c}(30) D_{i t c}+k_{0 t c}\left(A_{i}\right)+k_{1 t c}\left(A_{i}\right) 1\left\{A_{i}<30\right\}+v_{i t c}
$$

where $v_{i t c}=\left[Y_{i t c}-E\left(Y_{i t c} \mid A_{i}\right)\right]+\alpha_{t c}(30)\left[E\left(D_{i t c} \mid A_{i}\right)-D_{i t c}\right]+\left[E\left(\alpha_{i t c} D_{i t c} \mid A_{i}\right)-\alpha_{t c}\left(A_{i}\right) E\left(D_{i t c} \mid A_{i}\right)\right]$. $k_{0 t c}\left(A_{i}\right)+k_{1 t c}\left(A_{i}\right) 1\left\{A_{i}<30\right\}$ is the control function of age the shape of which differs on both sides of the discontinuity point $\left(k_{1 t c}\left(A_{i}\right) \neq 0\right)$ if the average treatment effect varies with age $\left(\alpha_{t c}\left(A_{i}\right) \neq \alpha_{t c}(30)\right)$.

The two-stage least squares procedure that uses the estimated propensity scores ${ }^{20}$ defined

\footnotetext{
${ }^{18}$ According to the theoretical month of notification (July, August, September or October 2004), $c$ can take on four different values for any given $t$.

${ }^{19}$ Note that the RD is only fuzzy to the left of the discontinuity point, since no individual older than 30 years is treated.

${ }^{20}$ Note that the propensity score for the group older than 30 years is exactly zero. The propensity score is therefore estimated on the sub-sample aged less than 30 years.
} 
in Equation (2) as instruments for the participation indicator in the second stage regression equation (3) consistently estimates the local average treatment effect $\alpha_{t c}(30)$ if three conditions are satisfied. First, $E\left(v_{i t c} \mid A\right)=0$ near $A=30$. A sufficient requirement for this is ${ }^{21}$

$$
\text { Assumption 1: } \quad E\left(\alpha_{i t c} \mid A, D\right)=E\left(\alpha_{i t c} \mid A\right) \equiv \alpha_{t c}(A) \quad \text { close to } \quad A=30
$$

This implies that the person specific impact of the notification $\alpha_{i t c}$ may not be correlated with the treatment $D_{i t c}$. We argue below that this assumption is likely to hold in this application.

For the two-stage least squares procedure to be consistent, two additional conditions must be satisfied (Hahn et al., 2001):

$$
\text { Assumption 2: } \quad k_{0 t c}(A) \text { and 3: } \quad \alpha_{i t c}(A) \text { are continuous at } A=30
$$

Intuitively, the continuity of these functions ensures that the discontinuity in the propensity score in (2) can be viewed as an exclusion restriction, since it ensures that the discontinuity can affect the outcome only indirectly via the treatment.

The continuity assumptions can be violated if the assignment to other policies is determined by the same cut off in the running variable. To our knowledge this is not the case. Moreover, we can check this by testing whether the significant treatment impacts at the cut off point disappear in the year prior to the introduction of the new monitoring scheme (see Section 6.2). Manipulation of the running variable is another reason that can make these functions discontinuous at the cut off (McCrary, 2007). If the selection rule on the running variable regarding participation in some program is publicly known, agents may change their behavior to qualify for or to avoid participation. This will affect the size and the composition of the population close to the cut off value of the running variable, which could result in a discontinuity in the functions reported in Equation (5). We will discuss this possibility in Section 6.3.

The two-stage least squares procedure provides consistent estimates of the local average treatment effect only if the functions $f_{t c}(),. k_{0 t c}($.$) and k_{1 t c}$ are correctly specified. We could estimate these functions semi-parametrically by local linear regression (Porter, 2003), but semi-parametric estimation involves a difficult trade-off between bias and precision. Moreover, given the relatively small sample size, a semi-parametric approach cannot much improve on a parametric one. We therefore follow, as Lemieux and Milligan (2006), the latter approach and perform a sensitivity analysis on five different specifications of $k_{0 t c}\left(A_{i}\right)+$

\footnotetext{
${ }^{21} E\left(\alpha_{i t c} D_{i t c} \mid A\right)=E\left[E\left(\alpha_{i t c} \mid A, D\right) D_{i t c} \mid A\right]=E\left(\alpha_{i t c} \mid A\right) E\left(D_{i t c} \mid A\right)=\alpha_{t c}\left(A_{i}\right) E\left(D_{i t c} \mid A\right)$, where the first equality follows from the law of iterated expectations and the second from assumption (4). Inserting this result in the expression for $E\left(v_{i t c} \mid A\right)$ yields the desired condition.
} 
$k_{1 t c}\left(A_{i}\right) 1\left\{A_{i}<30\right\}$ in regression Equation (3). The specifications include linear and quadratic splines (separate regressions on both sides of the discontinuity) and the standard linear, quadratic, and cubic functions, assuming that the average treatment effect does not vary with age, so that $\alpha_{t c}\left(A_{i}\right)=\alpha_{t c}(30)$ and therefore $k_{1 t c}\left(A_{i}\right)=0$. In addition, we also report for the preferred specification the estimated treatment effect obtained from a regression in which all observed explanatory variables are included as controls and, as a further robustness check (in Section 6), estimates for an increasingly small window around age 30. The function $f_{t c}($.$) in (2) is always specified by a polynomial of the same order as the one chosen$ for the regression equation of interest.

Even if the outcome and treatment variables are both binary, we nevertheless specify their relationship according to a linear probability model. The consistency of the estimator does not depend on any continuity assumption of the outcome variable (Hahn et al., 2001). Consistency requires, however, a correct specification of the propensity score of the treatment, i.e. of $f_{t c}($.$) . A polynomial linear in the parameters can by definition not be a correct speci-$ fication. However, since the results are not sensitive to specifying the propensity score as a probit or a logit, ${ }^{22}$ this is not a big issue.

The binary nature of the outcome variable renders the error term heteroskedastic. In addition, evaluating the outcome of the same individual $i$ at different time periods $t$, induces serial correlation. We therefore report the cluster-robust standard errors of the two-stage least squares estimator. ${ }^{23}$

In order to facilitate interpretation and to improve precision we will test and impose a number of parameter constraints. In the regression model in Equation (3) all the parameters depend on $t$, running from the $3^{\text {rd }}$ to the $8^{\text {th }}$ month after dispatch of the notification ${ }^{24}$ and on the calendar time $c$, depending on the timing of the (counterfactual) notification. Even if we always start our estimations from the most general formulation, we never will report results in which estimated treatment effects depend on $c$, since these restrictions can never be rejected at the $5 \%$ significance level. In addition, since we can neither reject independence of $t$ (between the $3^{r d}$ and $8^{\text {th }}$ month after dispatch of the notification letter), the evolution of the treatment effect is just reported graphically in Figure 1.

\footnotetext{
${ }^{22}$ These results are not reported, but can be obtained from the authors on request.

${ }^{23}$ In principle we should also adjust the standard errors to allow for the specification error induced by the grouping of age in monthly intervals (Lee and Card, 2006). However, since a robustness check in which we estimated the effect in one time period only revealed that standard errors are hardly affected when we allow for clustering within age-groups, we ignore the grouping over age.

${ }^{24}$ We do not consider the months prior to the $3^{\text {rd }}$ month after dispatch of the notification, since this would complicate the presentation of the results without adding fundamental insights: the restriction that the treatment effect is constant over calendar time $c$ is rejected during this initial period.
} 
In order to verify whether the treatment affects particular subgroups more than others, we also consider a model in which the treatment indicator $D_{i t c}$ is interacted with the observed characteristics of the unemployed workers. However, since the sample size is relatively small, we should sensibly restrict the number of interaction terms. We do this by first estimating for each Region a model with all interactions. Subsequently, we drop all interaction terms that are not (jointly) significant at the $10 \%$ significance level in any of the three Regions. This means that for some Regions insignificant terms may be retained as long as they are significant in one of the two other Regions. This ensures us a uniform presentation across Regions.

The model with interaction effects no longer identifies the local average treatment effect non-parametrically, since this would require to allow all the control functions in age to vary freely with every possible value of the characteristics retained in the interaction terms. This is clearly not feasible. To avoid that our inference is completely driven by the implicit parametric assumptions, we propose a procedure on the basis of which we can gauge whether these assumptions make sense.

The procedure consists first in predicting, on the basis of an interaction model, the treatment effect, constant over $t$ and $c$, for each sampled individual, treated or not. We then constitute sub-samples on the basis of particular percentiles of the distribution of the predicted treatment effects - we chose the $30 \%$ and the $70 \%$ percentile - and re-estimate on this sample the local average treatment effect using the model without interactions. The test consists in comparing on these sub-samples the last mentioned estimate of the treatment effect to the one obtained on the basis of the interaction model. If the interaction model is well specified these two estimates should be close. ${ }^{25}$

\section{The Results of the Benchmark Model and their Interpretation}

\subsection{What Does Theory Predict?}

Job search theory (see e.g. Mortensen, 1986; van den Berg, 1990) predicts that benefit claimants will modify their job-search intensity and acceptance behavior from the moment that they are informed of a future event that affects their welfare. Consequently, to avoid a sudden drop in their welfare induced by an intensified monitoring of job-search behavior, claimants should, from the moment of notification, accelerate their transition from unemployment to work (see Appendix). The empirical findings reported below for Flanders - where the notified group did not receive any specific counseling or assistance - match this prediction,

\footnotetext{
${ }^{25}$ Following this procedure, we detected a specification problem if we did not interact the treatment indicator with the indicator variable "recent interruption of UI".
} 
but only for the higher educated workers. For the lower educated workers, no significant impact is detected of the notification on the employment probability, presumably by lack of job opportunities for the lower skilled or because the lower educated require counseling to improve their job search effectiveness.

Counseling can enhance, cancel or even reverse the threat effect of the notification, depending on the moment it takes place. In Wallonia, the French speaking region in the south of Belgium, the unemployed workers are invited within two months of the notification for a collective information session. Subsequently, a caseworker of the Regional Employment Office counsels them personally on their job search strategy. If necessary, this is followed-up with further counseling and with participation in various types of training. Since counseling increases the effectiveness of job search, we expect it to reinforce the threat effect of the notification (see Appendix). We indeed find that in this Region the probability of employment is not only enhanced for the higher educated workers, but also for women and for workers with a recent work experience.

In Brussels the notified workers were also convoked to a collective information session within two months after the receipt of the letter. However, these workers were informed that they would be counseled only shortly after the monitoring interview that takes place roughly 8 months after dispatch of the notification letter. ${ }^{26}$ Announcing a start-up of the counseling at a later date may, however, be counterproductive and cancel or even reverse the threat effect. For, if counseling raises the effectiveness of job search, this will not only allow the worker to fulfill more easily the job search requirements imposed by the monitoring, but it will also raise the value of being unemployed. Now if the future option value of unemployment is enhanced, this decreases the incentive of the worker to search for a job today (see Appendix). Whether this occurs depends on the perceived effectiveness of the offered counseling and on the stringency of the search requirements: for some workers the threat effect of the monitoring may still dominate. The findings reported for Brussels are consistent with this story: the employment probabilities after dispatch of the notification are significantly lower than those of the control group except for women and singles. They demonstrate that it is crucial, in the design of a monitoring program, to accommodate the timing of the accompanying counseling program.

\footnotetext{
${ }^{26}$ The Brussels' Employment Office coped with capacity problems, because it decided to invite since February 2004 all workers below the age of 50 and before being unemployed for longer than 3 months to an intake interview in which an individual action plan is started up.
} 
Table 2: Local Average Treatment Effects on the Probability of Employment

\begin{tabular}{|c|c|c|c|c|c|c|c|}
\hline Region & (1) & (2) & (3) & $\begin{array}{c}(4) \\
\text { Brussels }\end{array}$ & (5) & (6) & (7) \\
\hline $\begin{array}{l}\text { Outcome without treatment } \\
\text { (standard error) }\end{array}$ & & & & $\begin{array}{c}0.227 \\
(0.023)\end{array}$ & & & \\
\hline$\alpha(30)$ & -0.076 & -0.077 & -0.033 & -0.034 & -0.034 & -0.065 & -0.046 \\
\hline (standard error) & $(0.070)$ & $(0.069)$ & $(0.046)$ & $(0.045)$ & $(0.045)$ & $(0.060)$ & $(0.044)$ \\
\hline Polynomial order & 2 & 2 & 1 & 1 & 2 & 3 & 1 \\
\hline Spline & Yes & Yes & Yes & No & No & No & No \\
\hline Polynomial specific by $\mathrm{t}$ and $\mathrm{c}$ & Yes & No & No & No & No & No & No \\
\hline Control variables & No & No & No & No & No & No & Yes \\
\hline Number of observations & & & & 8076 & & & \\
\hline \multirow[t]{2}{*}{ Number of individuals } & & & & 1346 & & & \\
\hline & & & & Flanders & & & \\
\hline $\begin{array}{l}\text { Outcome without treatment }{ }^{(a)} \\
\text { (standard error) }\end{array}$ & & & & $\begin{array}{c}0.291 \\
(0.017)\end{array}$ & & & \\
\hline$\alpha(30)$ & 0.063 & 0.062 & 0.034 & 0.036 & 0.034 & 0.052 & 0.041 \\
\hline (standard error) & $(0.053)$ & $(0.053)$ & $(0.035)$ & $(0.035)$ & $(0.035)$ & $(0.047)$ & $(0.034)$ \\
\hline Polynomial order & 2 & 2 & 1 & 1 & 2 & 3 & 1 \\
\hline Spline & Yes & Yes & Yes & No & No & No & No \\
\hline Polynomial specific by $t$ and $c$ & Yes & No & No & No & No & No & No \\
\hline Control variables & No & No & No & No & No & No & Yes \\
\hline Number of observations & & & & 15114 & & & \\
\hline \multirow[t]{2}{*}{ Number of individuals } & & & & 2519 & & & \\
\hline & & & & Wallonia & & & \\
\hline Outcome without treatment ${ }^{\text {(a) }}$ & & & & 0.222 & & & \\
\hline (standard error) & & & & $(0.016)$ & & & \\
\hline$\alpha(30)$ & 0.040 & 0.039 & 0.034 & 0.036 & 0.034 & 0.032 & 0.042 \\
\hline (standard error) & $(0.047)$ & $(0.047)$ & $(0.033)$ & $(0.033)$ & $(0.033)$ & $(0.042)$ & $(0.031)$ \\
\hline Polynomial order & 2 & 2 & 1 & 1 & 2 & 3 & 1 \\
\hline Spline & Yes & Yes & Yes & No & No & No & No \\
\hline Polynomial specific by $\mathrm{t}$ and $\mathrm{c}$ & Yes & No & No & No & No & No & No \\
\hline Control variables & No & No & No & No & No & No & Yes \\
\hline Number of observations & & & & 14478 & & & \\
\hline Number of individuals & & & & 2413 & & & \\
\hline
\end{tabular}

\subsection{The Local Average Treatment Effect on the Employment Probability}

Table 2 reports the local average impact of the notification between 3 to 8 months after the moment of dispatch on the probability of employment as defined in Section 3.3. The estimations are based on observations in a window of five years above and below the discontinuity point at 30 years. Section 6.1 analyzes whether the results are sensitive to the width of this observation window. The number of observations is the number of individuals multiplied by the 6 observation months, i.e. 3 to 8 months after dispatch of the notification. In Wallonia the estimates are very stable across the different specifications. In the other two Regions they are roughly double as large in absolute value in the more flexible specifications, but this sensitivity is negligible given the precision of the estimates. Even if the average impacts are never significantly different from zero, it is interesting to note that, if we take our 
Table 3: Heterogeneous Treatment Effects on the Probability of Employment

\begin{tabular}{|c|c|c|c|c|c|c|c|c|c|}
\hline \multirow{2}{*}{$\frac{\text { Panel A }}{\text { Parameter Estimates }^{(a)}}$} & \multicolumn{3}{|c|}{ Brussels } & \multicolumn{3}{|c|}{ Flanders } & \multicolumn{3}{|c|}{ Wallonia } \\
\hline & \multirow{3}{*}{\multicolumn{3}{|c|}{$\begin{array}{l}-0.107 \\
(0.070)\end{array}$}} & \multirow{3}{*}{\multicolumn{3}{|c|}{$\begin{array}{c}0.003 \\
(0.054)\end{array}$}} & \multirow{2}{*}{\multicolumn{3}{|c|}{0049}} \\
\hline \multirow{2}{*}{$\begin{array}{l}\text { Reference } \\
\text { (standard error) }\end{array}$} & & & & & & & & & \\
\hline & & & & & & & \multicolumn{3}{|c|}{$(0.056)$} \\
\hline \multirow{2}{*}{\multicolumn{2}{|c|}{$\begin{array}{l}\text { Women } \\
\text { (standard error) }\end{array}$}} & \multicolumn{2}{|l|}{$0.124^{* * *}$} & \multicolumn{3}{|c|}{0.027} & \multicolumn{3}{|c|}{$0.078^{* *}$} \\
\hline & & \multicolumn{2}{|l|}{$(0.043)$} & \multicolumn{3}{|c|}{$(0.035)$} & \multicolumn{3}{|c|}{$(0.033)$} \\
\hline Higher education & \multirow{2}{*}{\multicolumn{3}{|c|}{$\begin{array}{l}-0.027 \\
(0.062)\end{array}$}} & \multirow{2}{*}{\multicolumn{3}{|c|}{$\begin{array}{l}\mathbf{0 . 1 1 6}^{* *} \\
(0.048)\end{array}$}} & & 0.067 & \\
\hline (standard error) & & & & & & & \multicolumn{3}{|c|}{$\begin{array}{c}0.067 \\
(0.048)\end{array}$} \\
\hline Living alone & \multicolumn{3}{|c|}{$0.138^{* * *}$} & \multicolumn{3}{|c|}{0.028} & \multirow{2}{*}{\multicolumn{3}{|c|}{$\begin{array}{c}0.028 \\
0.037)\end{array}$}} \\
\hline (standard error) & \multicolumn{3}{|c|}{$(0.046)$} & \multicolumn{3}{|c|}{$(0.039)$} & & & \\
\hline Unemployment duration & \multirow{2}{*}{\multicolumn{3}{|c|}{$\begin{array}{l}-0.002 \\
(0.004)\end{array}$}} & \multirow{2}{*}{\multicolumn{3}{|c|}{$\begin{array}{l}-0.002 \\
(0.003)\end{array}$}} & \multicolumn{3}{|c|}{$-0.007^{* *}$} \\
\hline (standard error) & & & & & & & & $(0.003)$ & \\
\hline Recent UI interruption & \multirow{2}{*}{\multicolumn{3}{|c|}{$\begin{array}{l}-0.003 \\
(0.043)\end{array}$}} & \multicolumn{3}{|c|}{$0.067^{*}$} & & $0.104^{* * *}$ & \\
\hline (standard error) & & & & & & & & $(0.034)$ & \\
\hline Number of observations & & 8076 & & & 15114 & & & 14478 & \\
\hline Number of individuals & & 1346 & & & 2519 & & & 2413 & \\
\hline Panel B & (1) & $(2)$ & (3) & (1) & $(2)$ & (3) & (1) & $(2)$ & (3) \\
\hline Treatment Effects & & & & & & & & & \\
\hline $\begin{array}{l}\text { "Parametric" effect }{ }^{(\mathrm{b})} \\
\text { (standard error) }\end{array}$ & $\begin{array}{l}-\mathbf{0 . 1 4 4} \\
(0.051)\end{array}$ & $\begin{array}{l}-0.037 \\
(0.043)\end{array}$ & $\begin{array}{c}0.044 \\
(0.053)\end{array}$ & $\begin{array}{c}-0.012 \\
(0.041)\end{array}$ & $\begin{array}{c}0.045 \\
(0.035)\end{array}$ & $\begin{array}{l}\mathbf{0 . 1 1 5}^{* * *} \\
(0.043)\end{array}$ & $\begin{array}{l}-0.048 \\
(0.038)\end{array}$ & $\begin{array}{c}0.040 \\
(0.032)\end{array}$ & $\begin{array}{l}\mathbf{0 . 1 2 3}^{* * *} \\
(0.038)\end{array}$ \\
\hline $\begin{array}{l}\text { "Non-parametric" effect }{ }^{(\mathrm{c})} \\
\text { (standard error) }\end{array}$ & $\begin{array}{l}-0.210^{* *} \\
(0.082)\end{array}$ & $\begin{array}{l}-0.046 \\
(0.044)\end{array}$ & $\begin{array}{c}0.059 \\
(0.081)\end{array}$ & $\begin{array}{c}0.010 \\
(0.067)\end{array}$ & $\begin{array}{c}0.041 \\
(0.034)\end{array}$ & $\begin{array}{c}0.085 \\
(0.066)\end{array}$ & $\begin{array}{l}-0.016 \\
(0.055)\end{array}$ & $\begin{array}{c}0.042 \\
(0.031)\end{array}$ & $\begin{array}{c}\mathbf{0 . 1 1 2}^{*} \\
(0.057)\end{array}$ \\
\hline Outcome without treatment & 0.295 & 0.228 & 0.177 & 0.318 & 0.287 & 0.275 & 0.230 & 0.220 & 0.216 \\
\hline (standard error) & $(0.030)$ & $(0.022)$ & $(0.028)$ & $(0.021)$ & $(0.017)$ & $(0.023)$ & $(0.021)$ & $(0.016)$ & $(0.022)$ \\
\hline Panel C & (1) & (2) & (3) & (1) & $(2)$ & (3) & (1) & $(2)$ & (3) \\
\hline Descriptive Statistics & & & & & & & & & \\
\hline Women & $2.7 \%$ & $46.7 \%$ & $52.8 \%$ & $31.7 \%$ & $52.5 \%$ & $62.4 \%$ & $16.8 \%$ & $46.0 \%$ & $74.1 \%$ \\
\hline Higher education & $16.6 \%$ & $19.3 \%$ & $15.0 \%$ & $0.0 \%$ & $19.4 \%$ & $62.2 \%$ & $2.2 \%$ & $19.3 \%$ & $43.5 \%$ \\
\hline Living alone & $1.0 \%$ & $37.4 \%$ & $85.9 \%$ & $11.2 \%$ & $23.6 \%$ & $33.6 \%$ & $31.3 \%$ & $25.8 \%$ & $31.1 \%$ \\
\hline Unemployment duration & 14.8 & 13.5 & 11.5 & 15.9 & 13.1 & 13.1 & 16.4 & 13.1 & 11.0 \\
\hline Recent UI interruption & $41.3 \%$ & $35.4 \%$ & $29.4 \%$ & $0.0 \%$ & $29.9 \%$ & $51.9 \%$ & $0.3 \%$ & $30.0 \%$ & $57.1 \%$ \\
\hline Number of individuals & 404 & 1346 & 453 & 706 & 2519 & 776 & 721 & 2413 & 750 \\
\hline
\end{tabular}

(1) Sub-sample of the $30 \%$ lowest treatment effects.

(2) Total sample of (potentially) notified UI claimants aged 25-34 years.

(3) Sub-sample of the $30 \%$ highest treatment effects.

(a) Estimated with a linear polynomial in age.

(b) Local average treatment effect for a claimant aged 30 deduced from a model with treatment interactions.

(c) Local average treatment effect for a claimant aged 30 deduced from a model without treatment interactions. The "nonparametric" effects reported in columns (2) correspond to the ones in column (7) of Table 2.

* Significant at the $10 \%$ level.

** Significant at the $5 \%$ level.

*** Significant at the $1 \%$ level.

preferred estimate reported in the last column, ${ }^{27}$ the point estimates suggest that the notification increases the employment probability by roughly four percentage points in Flanders and Wallonia, whereas it decreases the employment probability by roughly five percentage points in Brussels. This reflects the different way in which the Regional PES have accommodated to the reform of the monitoring scheme. In Wallonia the threat effect of the notification is as large as in Flanders even if its unemployment rate is double as high as in in Flanders. We argue that this is due to the specific assistance, absent in Flanders, that the Walloon PES provides to the target group. The negative impact in Brussels is consistent with the inappropriate timing of the counseling, as discussed in the theoretical model. 


\subsection{Heterogenous Treatment Effects}

The fact that the average treatment effects are not significantly different from zero is partly explained by the lack of precision of our estimates resulting from the small sample size. Another explanation is that the average conceals heterogeneity of the treatment effect. We indeed find that the policy reform does affect the employment probability of particular groups, while it does not of others or it does so negatively.

Table 3 contains the results of the model with treatment interactions. Panel A reports the retained interaction coefficients. In panel B one can find the corresponding local average treatment effects for three samples: (1) the sub-sample of the 30\% lowest treatment effects (calculated on the basis of the model with treatment interactions); (2) the total sample of (potentially) notified UI claimants aged 25-35 years; (3) the sub-sample of the 30\% highest treatment effects. Estimates are reported for the models with and without treatment interaction terms. We denote the former as the "parametric" treatment effect, since it implicitly assumes a parametric form for the interaction terms of the treatment and of the (linear) polynomial in age. The latter is "non-parametric" in that it does not include interaction terms. Since the parameter estimates obtained with these two methods are always very close, we can confidently rely on the results from the parametric specification. Finally, panel $\mathrm{C}$ contains for the three (sub-)samples descriptive statistics of the retained interaction variables. This enables to compare the composition of the sub-samples of the $30 \%$ lowest and highest effects in, respectively column (1) and (3), with that of the full sample in column (2).

In Flanders we measure the "pure" threat effect of the notification, since the Regional PES did not provide any specific assistance to the target group. The treatment effect is only significant for high educated claimants (and also for those with a recent interruption of the UI spell, but less so). The employment probability of the group with the 30\% highest treatment effects increases with $11.5 \%$ (column (3), Panel B), from $27.5 \%$ to $39 \%$. For the other groups, reported in columns (1) and (2), no significant effects are detected.

In Wallonia the target group receives specific counseling and training. Despite the much higher unemployment rate in this Region, the additional assistance enhances employment for a wider group of benefit claimants: not only for highly educated workers, but also for women and for claimants with a recent employment experience (short unemployment duration and recent UI interruption). The employment probability of the group with the $30 \%$ highest effects increases on average by $12.3 \%$. In contrast with that of other groups, this ef-

\footnotetext{
${ }^{27}$ We prefer this specification, since higher order terms of the polynomial in age or the separate polynomials on both sides of the discontinuity point (splines) are never significant at the $5 \%$ level of significance and including controls increases (slightly) the precision.
} 
Figure 1: The Time-Profile of the Effect for Claimants with the 30\% Highest (Flanders and Wallonia) and Lowest (Brussels) Effects

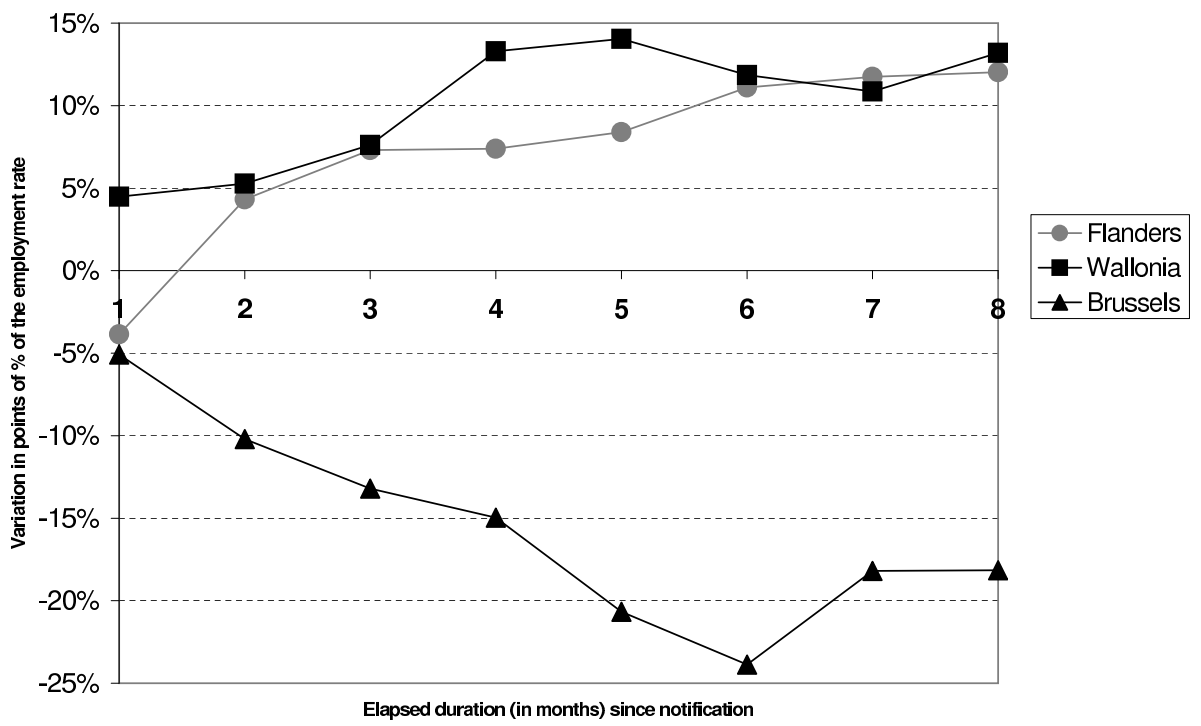

fect is significantly different from zero.

In Brussels the PES counteracts the threat effect of monitoring by announcing to the recipients of the notification letter that they will be counseled roughly at the same moment at which their search behavior will be monitored. This is especially the case for men and claimants living with other adults or with children (and who are therefore not single): these groups are over-represented within the group with the $30 \%$ lowest effects. On average the employment probability of the latter group is $14.4 \%$ lower than in the absence of policy reform. Even if the effect is very imprecisely estimated, it's significant at the $5 \%$ level.

Up to this point we always reported the average of the treatment effect between the $3^{r d}$ and the $8^{t h}$ month after notification, since a constant treatment effect could not be rejected statistically. The theoretical model in the Appendix predicts, however, that the job search intensity should, as one approaches the monitoring interview, monotonically increase in Flanders and Wallonia, and decrease in Brussels. This should result in an increasing profile of employment probability over the observation period. ${ }^{28}$ Figure 1, reporting the time-profile of the treatment effect for the 30\% highest (Flanders and Wallonia) and lowest (Brussels) effects, is consistent with this prediction of the theoretical model.

\footnotetext{
${ }^{28}$ If the transition rate from employment is not negatively affected, this should even increase the employment probability at an increasing rate. However, our estimates are not precise enough to test this prediction.
} 
Table 4: RD-Estimates with Different Age Windows

\begin{tabular}{|c|c|c|c|c|c|c|}
\hline Brussels & $\begin{array}{c}(1) \\
\text { \# obs. }\end{array}$ & $\begin{array}{c}(2) \\
\text { \# indiv. }\end{array}$ & (3) & (4) & (5) & (6) \\
\hline \pm 1 year & 1458 & 243 & $\begin{array}{l}-0.062 \\
(0.051)\end{array}$ & $\begin{array}{l}-0.082 \\
(0.049)\end{array}$ & $\begin{array}{l}-0.083 \\
(0.108)\end{array}$ & $\begin{array}{l}-0.120 \\
(0.098)\end{array}$ \\
\hline \pm 2 years & 3186 & 531 & $\begin{array}{c}0.005 \\
(0.033)\end{array}$ & $\begin{array}{l}-0.003 \\
(0.033)\end{array}$ & $\begin{array}{l}-0.099 \\
(0.072)\end{array}$ & $\begin{array}{l}-0.111^{*} \\
(0.067)\end{array}$ \\
\hline \pm 3 years & 4866 & 811 & $\begin{array}{c}0.021 \\
(0.028)\end{array}$ & $\begin{array}{c}0.012 \\
(0.028)\end{array}$ & $\begin{array}{l}-0.075 \\
(0.058)\end{array}$ & $\begin{array}{l}-0.090 \\
(0.055)\end{array}$ \\
\hline \pm 4 years & 6534 & 1089 & $\begin{array}{c}0.018 \\
(0.024)\end{array}$ & $\begin{array}{c}0.010 \\
(0.024)\end{array}$ & $\begin{array}{l}-0.034 \\
(0.050)\end{array}$ & $\begin{array}{l}-0.046 \\
(0.048)\end{array}$ \\
\hline \pm 5 years & 8076 & 1346 & $\begin{array}{c}0.030 \\
(0.021)\end{array}$ & $\begin{array}{c}0.016 \\
(0.022)\end{array}$ & $\begin{array}{l}-0.034 \\
(0.045)\end{array}$ & $\begin{array}{l}-0.046 \\
(0.044)\end{array}$ \\
\hline \multicolumn{7}{|l|}{ Flanders } \\
\hline \pm 1 year & 2922 & 487 & $\begin{array}{c}0.070^{*} \\
(0.038)\end{array}$ & $\begin{array}{l}0.076^{* *} \\
(0.038)\end{array}$ & $\begin{array}{c}0.105 \\
(0.078)\end{array}$ & $\begin{array}{c}0.119 \\
(0.076)\end{array}$ \\
\hline \pm 2 years & 5664 & 944 & $\begin{array}{c}0.045 \\
(0.028)\end{array}$ & $\begin{array}{c}0.051^{*} \\
(0.028)\end{array}$ & $\begin{array}{c}0.128^{* *} \\
(0.055)\end{array}$ & $\begin{array}{c}0.135^{* *} \\
(0.054)\end{array}$ \\
\hline \pm 3 years & 8604 & 1434 & $\begin{array}{l}0.077^{* * *} \\
(0.023)\end{array}$ & $\begin{array}{l}0.077^{* * * *} \\
(0.022)\end{array}$ & $\begin{array}{c}0.041 \\
(0.046)\end{array}$ & $\begin{array}{c}0.051 \\
(0.045)\end{array}$ \\
\hline \pm 4 years & 11874 & 1979 & $\begin{array}{l}0.105^{* * *} \\
(0.019)\end{array}$ & $\begin{array}{l}0.099^{* * * *} \\
(0.019)\end{array}$ & $\begin{array}{c}0.026 \\
(0.039)\end{array}$ & $\begin{array}{c}0.036 \\
(0.038)\end{array}$ \\
\hline \pm 5 years & 15114 & 2519 & $\begin{array}{l}0.115^{* * *} \\
(0.017)\end{array}$ & $\begin{array}{l}0.109^{* * * *} \\
(0.017)\end{array}$ & $\begin{array}{c}0.036 \\
(0.035)\end{array}$ & $\begin{array}{c}0.041 \\
(0.034)\end{array}$ \\
\hline \multicolumn{7}{|l|}{ Wallonia } \\
\hline \pm 1 year & 2676 & 446 & $\begin{array}{c}0.043 \\
(0.036)\end{array}$ & $\begin{array}{c}0.059^{*} \\
(0.035)\end{array}$ & $\begin{array}{c}0.091 \\
(0.071)\end{array}$ & $\begin{array}{c}0.148^{* *} \\
(0.067)\end{array}$ \\
\hline \pm 2 years & 5556 & 926 & $\begin{array}{c}0.058^{* *} \\
(0.026)\end{array}$ & $\begin{array}{l}0.055^{* *} \\
(0.026)\end{array}$ & $\begin{array}{c}0.034 \\
(0.050)\end{array}$ & $\begin{array}{c}0.047 \\
(0.048)\end{array}$ \\
\hline \pm 3 years & 8274 & 1379 & $\begin{array}{l}0.071^{* * *} \\
(0.021)\end{array}$ & $\begin{array}{c}0.068^{* * * *} \\
(0.021)\end{array}$ & $\begin{array}{c}0.033 \\
(0.041)\end{array}$ & $\begin{array}{c}0.049 \\
(0.040)\end{array}$ \\
\hline \pm 4 years & 11316 & 1886 & $\begin{array}{l}0.082^{* * *} \\
(0.018)\end{array}$ & $\begin{array}{l}0.071^{* * * *} \\
(0.018)\end{array}$ & $\begin{array}{c}0.029 \\
(0.036)\end{array}$ & $\begin{array}{c}0.039 \\
(0.035)\end{array}$ \\
\hline \pm 5 years & 14478 & 2413 & $\begin{array}{l}0.092^{* * * *} \\
(0.016)\end{array}$ & $\begin{array}{l}0.078^{* * *} \\
(0.016)\end{array}$ & $\begin{array}{c}0.036 \\
(0.033)\end{array}$ & $\begin{array}{c}0.042 \\
(0.031)\end{array}$ \\
\hline \multicolumn{7}{|l|}{ Controls : } \\
\hline Age (linear) & & & No & No & Yes & Yes \\
\hline Other & & & No & Yes & No & Yes \\
\hline
\end{tabular}

\section{Robustness Checks and Extensions}

\subsection{Narrowing the Window of the Running Variable, Age}

The discontinuity approach is arguably more convincing the closer the observations to the discontinuity point. However, there is a trade-off between bias and precision. For a narrow observation window the bias introduced by not or incorrectly controlling for age is smaller, but this comes at a cost of precision, since the number of observations is relatively smaller. In Table 4 we report the local average treatment effect for sub-samples selected within an increasingly narrow age window around the discontinuity point at 30 years. The discontinuity sample \pm 1 (abbreviated as DS \pm 1 ) consists of the treatment group of 29-year-olds and the control group of 30-year-olds; DS \pm 2 includes the 28- and 29-year-olds in the treatment 
group and the 30- and 31-year-olds in the control group. DS $\pm 3, \mathrm{DS} \pm 4$ and DS \pm 5 are defined similarly. Columns (1) and (2) state, respectively, the total number of individuals and observations. For each sample we report the results for four different specifications. The specifications underlying columns (5) and (6) contain a linear term in age, whereas those of columns (3) and (4) do not. The results reported in columns (4) and (6) differ from those reported in columns (3) and (5) in that they include all explanatory variables mentioned in Table 1 as additional control variables.

The results confirm that the findings are not sensitive to including or not the non-age control variables in the regression equation and that that the precision is in general only mildly increased. For the sub-samples close to the discontinuity point the estimated treatment effects of the models ignoring the control for age are similar to the ones constructed from a wider age-window (DS \pm 4 and DS \pm 5 ) for which the age controls are included. This is reassuring, since the narrower the age window, the less important it is to control for differences in age.

The fact that the estimates in columns (3) and (4) deviate from those in columns (5) and (6) is quite intuitive for the wide age windows, since age differences become more important. However, for the narrower age windows (DS \pm 1 and DS \pm 2 ), the estimates with the control functions in age are also systematically larger in absolute value, except for the DS \pm 2 in Wallonia. We put forward two explanations. First, the standard errors of the effects are also much larger, so that the smaller point estimates are always enclosed by the $95 \%$ confidence interval. Second, the linear polynomial in age was the preferred one for the widest age window. There is no reason why it should be for narrower age windows.

\subsection{Falsification Test in the Year Prior to the Reform}

We mentioned in Section 4 that the continuity assumption can be violated if the assignment to other policies is determined by the same cut off in the running variable. We check this by repeating the RD analysis on a sample of benefit claimants aged between 25 and 34 in 2003 to whom the federal UA would have dispatched a notification if the new monitoring scheme had been put into force for this age group already in 2003. Table 5 reports our findings. The local average treatment effects at 30 are never significantly different from zero. They are extremely small in Flanders and in Wallonia, and slightly positive in Brussels. This is reassuring. However, even if in 2004 these effects were larger in absolute value, they were never significant. We therefore checked whether the effects remain insignificant for the same sub-populations for which we reported significant treatment effects in 2004 . We confirm that this is the case. ${ }^{29}$

\footnotetext{
${ }^{29}$ These results can be obtained from the authors upon request.
} 
Table 5: Falsification Test: RD-Estimates ${ }^{\dagger}$ in the Year Prior to the Reform, 2003

\begin{tabular}{lcccccc} 
& \multicolumn{2}{c}{ Brussels } & \multicolumn{2}{c}{ Flanders } & \multicolumn{2}{c}{ Wallonia } \\
& $\mathbf{2 0 0 4}$ & $\mathbf{2 0 0 3}$ & $\mathbf{2 0 0 4}$ & $\mathbf{2 0 0 3}$ & $\mathbf{2 0 0 4}$ & $\mathbf{2 0 0 3}$ \\
\hline$\alpha(30)$ & -0.046 & 0.025 & 0.041 & 0.001 & 0.042 & -0.005 \\
(standard error) & $(0.044)$ & $(0.037)$ & $(0.034)$ & $(0.030)$ & $(0.031)$ & $(0.027)$ \\
\# obs. & 8076 & 7926 & 15114 & 15252 & 14478 & 15114 \\
\# indiv. & 1346 & 1321 & 2519 & 2542 & 2413 & 2519 \\
\hline \multicolumn{2}{r}{$\dagger$ Specification with linear polynomial in age and control variables. }
\end{tabular}

\subsection{Testing for Manipulation of the Running Variable}

The RD approach is only valid to the extent that the intended treatment population cannot change it's behavior - "manipulate the running variable" - as to avoid (or to benefit from) the treatment. In this study the running variable, age, can not be manipulated directly, but can be indirectly since assignment to the treatment is not solely based on age, but also on being a benefit claimant for 13 months or more (if one is older than 25). This unemployment duration can be manipulated if the unemployed workers anticipate the dispatch of the notification and leave unemployment even before receiving the notification or postpone this transition. ${ }^{30}$ This would reduce, respectively increase, the size of the treated population and change its composition. ${ }^{31}$

We test whether manipulation of the running variable is an issue in three ways. First, since the sample is selected two to three months before dispatch of the notification (cf. Section 3.1), we can verify whether the workers below the age of 30 years already have a higher employment probability than the older group before the treatment, i.e. the moment at which the notification is dispatched. Second, we apply the McCrary's test on the continuity of the density of the running variable. ${ }^{32}$ Thirdly, in order to test for composition effects, we test whether the predetermined characteristics (reported in Table 1) are smooth around the cutoff age. Table 6 reports the local average treatment effect on the probability of employment one to two months before dispatch of the notification. The point estimates are very close to zero and never significant. We obtain similar findings if we focus on the sub-groups for which we detected significant treatment effects after dispatch of the notification. ${ }^{33}$

Figure 2 reports for each Region the number of sampled benefit recipients by age (expressed

\footnotetext{
${ }^{30}$ If the treatment is not perceived as a threat, but as a benefit - as it may be for a number of claimants in Brussels - the transition from unemployment may be postponed instead of accelerated.

${ }^{31}$ More educated workers, e.g., have more opportunities to leave unemployment as a result of the threat then less educated ones.

${ }^{32}$ We can only approximate this density, since we cannot observe the size of the total population at a particular age as measured on July 1, 2004. However, as long as this size does not vary discontinuously with age this shouldn't matter for the test.

${ }^{33}$ These results can be obtained from the authors upon request.
} 
Table 6: Anticipation Effects 1 to 2 Months Before the Month of (Potential) Notification ${ }^{\dagger}$

\begin{tabular}{lcccccc} 
& \multicolumn{2}{c}{ Brussels } & \multicolumn{2}{c}{ Flanders } & \multicolumn{2}{c}{ Wallonia } \\
\hline & $(1)$ & $(2)$ & $(1)$ & $(2)$ & $(1)$ & $(2)$ \\
$\alpha(30)$ & 0.003 & 0.001 & -0.025 & -0.023 & 0.002 & 0.008 \\
(standard error) & $(0.022)$ & $(0.022)$ & $(0.019)$ & $(0.018)$ & $(0.017)$ & $(0.016)$ \\
\# obs. & 4572 & 4572 & 9423 & 9423 & 8478 & 8478 \\
\# indiv. & 1524 & 1524 & 3141 & 3141 & 2826 & 2826 \\
\hline Controls & No & Yes & No & Yes & No & Yes \\
\multicolumn{1}{r}{$\dagger$ Specification with linear polynomial in age. } & & &
\end{tabular}

in months) around the point of discontinuity at 360 months (= 30 years). We cannot discern any discontinuity. This finding is confirmed in a formal regression analysis, reported in the first line of Table A- 1 in the Appendix. This table also reports the local average treatment effects for all the predetermined variables reported in Table 1. Apart from the variables "men" and "lower secondary education" in Flanders and "cohabitant" in Wallonia, none of the point estimates are significantly different from zero at a P-level of $10 \%$. We are therefore confident that the smoothness assumption is satisfied and that the composition is not affected prior to the sampling date.

\subsection{Testing for Substitution Effects}

In the RD analysis we implicitly assume that the members of the control group are not affected by the treatment and that the members of the treatment group are only affected by their own treatment and not by the treatment of others: it is assumed that external treatment effects are absent. This assumption is violated if the notification and the specific counseling induces substitution. For instance, it is possible that notified (and/or counseled) benefit claimants are hired at the expense of the non-notified ones. If so, the estimates of the local average treatment effect on the basis of the RD analysis is biased upwards, since part of the difference between the treated and the controls is induced by the lower employment rate of the controls. The treatment effect can also be downward biased. For instance, it is possible that benefit recipients older than 30 years in Wallonia have also benefited from the enhanced supply of counseling and training.

To test for the presence of substitution effects, we follow Leuven and Oosterbeek (2004) by assuming that benefit recipients who are at least 10 years older than the treated population are not affected by the policy reform. In addition, we assume that, in the absence of the policy reform, the profile of the employment probability with age for the group aged between 30 and 34 would have undergone a parallel shift between 2003 and 2004 of the same size as the one observed for the group aged between 39 and 43 years, at least 10 years older than the the treated population aged between 25 and $29 .{ }^{34}$ With these assumptions the external

\footnotetext{
${ }^{34}$ This corresponds to Assumptions 1c and 2c in Leuven and Oosterbeek (2004).
} 
Figure 2: Testing the Continuity of the Running Variable: The Number of Individuals by Age (in Months)

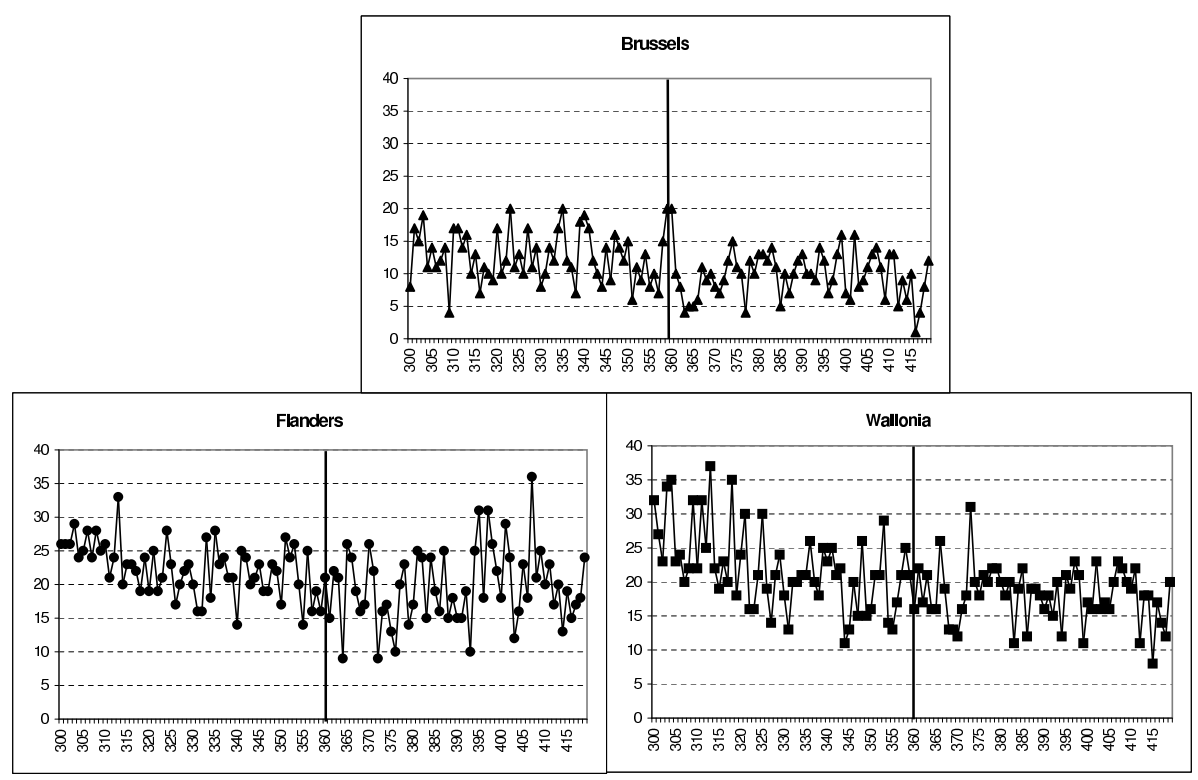

treatment effect of the threat of monitoring (possibly combined with intensified counseling) can be estimated by a difference-in-differences (DID) estimator. The assumption that the shift in the age-employment profile of the claimants aged between 30 and 34 corresponds to the one observed among the 39-43-year-olds can be challenged: Economic conditions were improving between 2003 and 2004 and the hiring rate of the young is generally more sensitive to the business cycle than of the older workers. The estimates of the substitution effects should therefore be considered as an upper bound. In Table 7 we report these DID estimates for an increasingly wide age window of untreated benefit recipients: We first consider the external treatment effect on the 30-year-olds, subsequently on the 30-31-year-olds, and so on, widening the interval each time by one year until we attain the 30-34 year age group. If substitution effects decrease with age, the estimates should decelerate towards zero the wider is the interval. On the other hand, the sensitivity of the age-employment profile to the business cycle should be less biased upwards the wider the age interval.

The reported point estimates are never significantly different from zero. In Brussels and Wallonia they are nearly all positive and more so the wider is the age interval. For these wider intervals we expect the upward bias to be the smallest. As a consequence, substitution is unlikely to be important in these Regions and if any it might rather be positive. On the other hand in Flanders the substitution effect is mostly negative, especially for the wider age-intervals. Consequently, should the threat of monitoring induce any employment 
Table 7: Substitution Effects on the Older Benefit Claimants ${ }^{\dagger}$

\begin{tabular}{lccc} 
Age group & Brussels & Flanders & Wallonia \\
\hline 30 & 0.012 & -0.025 & -0.015 \\
(standard error) & $(0.052)$ & $(0.037)$ & $(0.036)$ \\
\# obs. & 5718 & 15078 & 11934 \\
\# indiv. & 953 & 2513 & 1989 \\
\hline $30-31$ & 0.004 & 0.003 & 0.019 \\
(standard error) & $(0.038)$ & $(0.029)$ & $(0.027)$ \\
\# obs. & 7290 & 17646 & 14604 \\
\# indiv. & 1215 & 2941 & 2434 \\
\hline $30-32$ & 0.029 & -0.004 & 0.013 \\
(standard error) & $(0.033)$ & $(0.025)$ & $(0.024)$ \\
\# obs. & 8742 & 20478 & 17220 \\
\# indiv. & 1457 & 3413 & 2870 \\
\hline 30-33 & 0.031 & -0.026 & 0.022 \\
(standard error) & $(0.031)$ & $(0.023)$ & $(0.022)$ \\
\# obs. & 10194 & 23724 & 19638 \\
\# indiv. & 1699 & 3954 & 3273 \\
\hline 30-34 & 0.027 & -0.031 & 0.022 \\
(standard error) & $(0.029)$ & $(0.022)$ & $(0.021)$ \\
\# obs. & 11442 & 26556 & 22014 \\
\# indiv. & 1907 & 4426 & 3669 \\
\hline
\end{tabular}

$\dagger$ DID estimates with the $39-43$ age-group as controls.

of younger workers at the expense of older workers, this is most likely to happen in Flanders. On the other hand, the labor market is much tighter in Flanders than in the two other Regions. Theoretically we expect therefore less substitution in Flanders.

Finally, one could argue that the substitution effects are likely to be more important for the sub-groups for whom we found the highest treatment effects. We therefore verified whether the substitution effects for these groups are significantly different from zero. ${ }^{35}$ We retain for this analysis only the widest age window, i.e. the 30-34-year-olds. From this analysis we did not find significant effects for any of the sub-groups and Regions. We therefore conclude that if any substitution occurred, it cannot have been important.

\subsection{The Quality of Employment}

The threat of monitoring enhances the employment probability of high educated workers and, if it is combined with intensified counseling and training, other specific groups (women, unemployed people with recent work experience) may also benefit. One may, however, be concerned whether the higher likelihood of employment does not come at the expense of the quality of the job. We provide some partial evidence on the basis of the limited number indicators that are available: the probability of being employed for more than 3 or 6 months ${ }^{36}$

\footnotetext{
${ }^{35}$ The estimation results may be obtained from the authors upon request.

${ }^{36}$ As a consequence of the limited observation period, we can only observe this outcome for individuals who are employed not later than, respectively, the $7^{\text {th }}$ and the $4^{\text {th }}$ month after dispatch of the notification.
} 
Table 8: The Impact on the Quality of Employment ${ }^{\dagger}$

\begin{tabular}{|c|c|c|c|c|c|c|c|c|c|}
\hline \multirow[b]{2}{*}{ Impacts } & \multicolumn{3}{|c|}{ Employed > 3 months } & \multicolumn{3}{|c|}{ Employed $>6$ months } & \multicolumn{3}{|c|}{ Low-wage part-time job } \\
\hline & Brussels & Flanders & Wallonia & Brussels & Flanders & Wallonia & Brussels & Flanders & Wallonia \\
\hline Reference & -0.087 & 0.009 & 0.044 & -0.065 & 0.036 & 0.053 & -0.015 & 0.002 & -0.001 \\
\hline$(\text { s.e. })^{\ddagger}$ & $(0.065)$ & $(0.053)$ & $(0.054)$ & $(0.060)$ & $(0.050)$ & $(0.051)$ & $(0.024)$ & $(0.016)$ & $(0.017)$ \\
\hline Women & $0.088^{* *}$ & 0.021 & 0.051 & 0.048 & 0.024 & 0.027 & 0.015 & 0.001 & -0.003 \\
\hline (s.e.) & $(0.041)$ & $(0.034)$ & $(0.032)$ & $(0.038)$ & $(0.032)$ & $(0.030)$ & $(0.014)$ & $(0.011)$ & $(0.011)$ \\
\hline H. educ. & -0.027 & $0.136^{* * *}$ & 0.066 & -0.054 & $0.117^{* *}$ & 0.066 & 0.006 & $0.032^{* *}$ & 0.000 \\
\hline$(\text { s.e. })^{\ddagger}$ & $(0.060)$ & $(0.048)$ & $(0.047)$ & $(0.058)$ & $(0.047)$ & $(0.045)$ & $(0.015)$ & $(0.013)$ & $(0.015)$ \\
\hline Single & $0.112^{* *}$ & 0.046 & 0.024 & 0.055 & 0.040 & 0.018 & $0.029^{*}$ & 0.016 & -0.016 \\
\hline$(\text { s.e. })^{\ddagger}$ & $(0.044)$ & $(0.037)$ & $(0.035)$ & $(0.041)$ & $(0.034)$ & $(0.033)$ & $(0.016)$ & $(0.013)$ & $(0.013)$ \\
\hline Duration & -0.002 & -0.002 & $-0.008^{* * *}$ & 0.003 & -0.004 & $-0.007^{* *}$ & -0.000 & 0.001 & -0.000 \\
\hline$(\text { s.e. })^{\ddagger}$ & $(0.004)$ & $(0.003)$ & $(0.003)$ & $(0.003)$ & $(0.003)$ & $(0.003)$ & $(0.001)$ & $(0.001)$ & $(0.001)$ \\
\hline Interrupt. & -0.015 & 0.050 & $0.099^{* * * *}$ & -0.048 & 0.043 & $0.074^{* *}$ & 0.001 & -0.008 & $0.019^{*}$ \\
\hline$(\text { s.e. })^{\ddagger}$ & $(0.040)$ & $(0.034)$ & $(0.033)$ & $(0.038)$ & $(0.032)$ & $(0.031)$ & $(0.015)$ & $(0.011)$ & $(0.011)$ \\
\hline \multicolumn{10}{|c|}{ Outcome without treatment } \\
\hline & 0.175 & 0.207 & 0.174 & 0.114 & 0.138 & 0.121 & 0.016 & 0.013 & 0.018 \\
\hline$(\text { s.e. })^{\ddagger}$ & $(0.021)$ & $(0.017)$ & $(0.015)$ & $(0.019)$ & $(0.016)$ & $(0.014)$ & $(0.008)$ & $(0.005)$ & $(0.005)$ \\
\hline \# obs. & 6730 & 12595 & 12065 & 2692 & 5038 & 4826 & 8076 & 15114 & 14478 \\
\hline \# indiv. & 1346 & 2519 & 2413 & 1346 & 2519 & 2413 & 1346 & 2519 & 2413 \\
\hline
\end{tabular}

and the probability of being employed in a part-time low-wage job in which an income supplement is due (see Section 3.3). In order to focus on the effects of specific groups, we present only the model with interaction effects.

Table 8 reports our findings. First, we find mixed evidence in Flanders. On the one hand, the threat effect induces the high educated workers to enter more stable jobs, since the probability of being employed for more than 3 and 6 months is about as much enhanced as the benchmark indicator. This may follow from the fact that the threat of monitoring only disappears if the worker has been full-time employed for more than 12 months. ${ }^{37}$ On the other hand, the probability of part-time employment with income supplement is also higher. This suggests that the threat of monitoring may indeed lead to accepting lower quality jobs. However, further research is needed to confirm this finding.

In Wallonia the employment in low-wage part-time jobs is not stimulated. This can be a consequence of the counseling: the case workers may want to preclude that workers are pushed in lower quality jobs. On the other hand, despite the counseling, the program enhances employment in unstable jobs for women: the effect on the probability of being employed more than 3 or 6 months is no longer significantly different from zero. This may result from the rapid development of subsidized domestic assistance jobs since 2004 in Wallonia. These jobs

\footnotetext{
3.2 .

${ }^{37}$ See the discussion on the definition of unemployment duration used within the AJSB procedure in Section
} 
are predominantly filled by women and characterized by short-term contracts.

Finally, in Brussels no significant impact is observed on the probability of being employed in the part-time job with income supplement. More importantly, the likelihood of being employed more than 6 months is now no longer significantly negatively affected any group. This is consistent with the theory: It does not make sense to reject job offers with long-term employment prospects as to benefit from the counseling services offered later on.

\section{Conclusion}

In this paper we estimated the threat effect of intensified monitoring for unemployment benefit claimants close to 30 years old. We find that the pure threat effect only increases the probability of employment of the high educated workers and increasingly so as one approaches the moment at which the monitoring takes place. Since the threat of monitoring remains if one reverts to unemployment within a year, the threat does not seem to enhance employment in unstable jobs. However, the threat of monitoring seems to come at the expense of accepting lower quality jobs: the notification that monitoring will take place induces high educated benefit claimants to more easily accept part-time low-wage jobs.

The appropriate timing of the counseling is essential for the policy to be effective. If the benefit claimants are counseled briefly after being notified that a monitoring interview will take place within eight months, this favors employment for a larger group, in particular for the workers with a recent employment experience and for women. For women this policy only increases the transition to unstable jobs, not to stable ones. If the counseling is announced to take place shortly after the monitoring interview, claimants more reluctantly accept temporary jobs as to benefit from the assistance provided later on.

We conclude that this article has shown that, even if the literature suggests that monitoring itself does not increase the probability of employment, the threat of it (possibly combined with simultaneous counseling) can enhance it, be it for a group of more employable workers and less so for the more disadvantaged. Moreover, we found some indication that the pure threat effect of monitoring induces workers to accept jobs of lower quality, but that this negative effect can be undone by providing appropriate counseling. We must keep in mind, however, that these effects were measured right after the introduction of the policy reform. Threat effects may then have been of a different magnitude than currently, since claimants were uncertain at that time how harsh the monitoring would be. 


\section{Appendix}

In this Appendix we present a simple model that allows us to predict the effect of notifying a claimant that a monitoring interview will take place at later date on the evolution of the job-search effort prior to that date. We consider four cases:

1. The benchmark model without monitoring;

2. The impact of notifying the monitoring;

3. The impact of simultaneously counseling notified claimants;

4. The impact of announcing that both monitoring and counseling will take place at some future date.

The first model describes the behavior before the 2004 reform has taken place. The three subsequent ones aim at capturing a stylized form of the reforms, respectively in Flanders, Wallonia and Brussels.

\section{A-1 The benchmark model without monitoring}

Consider an unemployed worker claiming benefits $b$. Assume that claimants accept any proposed job offers $^{38}$ and that the job arrival rate is proportional to the job search effort $s: \lambda(s)=\lambda s$. Furthermore, assuming that the worker is risk-neutral, $z$ denotes the instantaneous utility of claiming unemployment benefits, including the value of domestic production and, possibly, undeclared labor income $(z>b)$. The cost arising from search effort is $c(s)$, where $c(0)=0, c^{\prime}>0$ and $c^{\prime \prime}>0$. In the absence of a monitoring scheme and assuming, for simplicity, an infinite time horizon, the continuous time expected lifetime utility of an unemployed worker at time $t$ is then defined by the following recursive relation:

$$
V_{u 0}(t)=\frac{1}{1+r d t} \operatorname{Max}_{s}\left\{[z-c(s)] d t+\lambda s d t V_{e}+(1-\lambda s d t) V_{u 0}(t+d t)\right\}
$$

where the subscript 0 stands for the benchmark model without monitoring, $r$ is the discount rate and $V_{e}$ is the expected lifetime utility of an employed worker. We do not specify $V_{e}$, but we just assume that, for all $t, V_{e}>V_{u 0}(t)$. This assumption ensures that claimants accept all job offers. Rearranging this relation, dividing by $d t$ and taking the limit for $d t \rightarrow 0$ yields

$$
r V_{u 0}(t)=\operatorname{Max}_{s}\left\{[z-c(s)]+\lambda s\left[V_{e}-V_{u 0}(t)\right]\right\}+\dot{V}_{u 0}(t)
$$

The optimal job search effort at time $t, s_{0}(t)$, must satisfy the following equation:

$$
\lambda\left[V_{e}-V_{u 0}(t)\right]=c^{\prime}\left[s_{0}(t)\right]
$$

The marginal return to effort is equal to the marginal cost. Since $V_{e}>V_{u 0}(t)$, the effort will be strictly positive everywhere. In addition, since all exogenous variables are stationary, the expected lifetime utility and job search effort are constant over time: $\dot{V}_{u 0}(t)=0$ and $s_{0}(t)=s_{0}$.

\footnotetext{
${ }^{38}$ This is not too strong an assumption. The probability of accepting job offers typically ranges between $90 \%$ and 100\% (see e.g. Devine, 1988; Wolpin, 1987; van den Berg, 1990).
} 


\section{A-2 The impact of notifying the monitoring}

Consider now that job search effort is monitored at some future moment $t=t_{m}>0$ and that the worker is notified hereof today, at time $t=0$. We make the simplifying assumption that the monitoring agency observes job search effort without error and that it just requires the level of effort to exceed a certain threshold $\bar{s}$ at any moment beyond $t_{m}: \forall t \geq t_{m}: s(t) \geq \bar{s} \cdot{ }^{39}$ If the level of effort is too low, the worker is sanctioned.

We now consider the impact of the new monitoring scheme on a worker for whom the search requirement is binding. We will show that the monitoring will affect the profile of job search $s_{1}(t)$ in the following way: at the moment of notification the job search effort will jump up; subsequently, it will rise gradually until the $t_{m}$; at $t_{m}$ it jumps up for a second time to the required level $\bar{s}$, at which it remains as long as the monitoring scheme is in force.

We solve the problem by backward induction. First observe that beyond $t_{m}$ the job search effort is fixed at the level of the search requirement and the expected lifetime utility, $V_{u 1}(t)$, is stationary. Since the search constraint is binding, we must have that approaching $t_{m}$ from the right, at $t=\lim _{d t \rightarrow 0}\left(t_{m}+d t\right) \equiv t_{m}^{+}$, the marginal return to job search must be lower than the marginal cost: $\lambda\left[V_{e}-V_{u 1}\left(t_{m}^{+}\right)\right]<c^{\prime}\left[s_{1}\left(t_{m}^{+}\right)\right]$. On the other hand, approaching $t_{m}$ from the left, at $t=\lim _{d t \rightarrow 0}\left(t_{m}-d t\right) \equiv t_{m}^{-}$ the search constraint will not bind and therefore $\lambda\left[V_{e}-V_{u 1}\left(t_{m}^{-}\right)\right]=c^{\prime}\left[s_{1}\left(t_{m}^{-}\right)\right]$. Since $V_{u 1}(t)$ is a state variable, we have that $V_{u 1}\left(t_{m}^{-}\right)=V_{u 1}\left(t_{m}^{+}\right)$. Inserting the above mentioned conditions on search effort in this equality yields $c^{\prime}\left[s_{1}\left(t_{m}^{-}\right)\right]<c^{\prime}\left[s_{1}\left(t_{m}^{+}\right)\right]$and therefore $s\left(t_{m}^{-}\right)<s\left(t_{m}^{+}\right)=\bar{s}$ : the job search effort jumps upwards at $t=t_{m}$.

We now prove that job search effort must be increasing as one approaches $t_{m}$. To do so we first show that the expected lifetime utility is strictly decreasing.

Proposition 1: $\forall t \leq t_{m}: \dot{V}_{u 1}(t)<0$

Proof:

1. $\dot{V}_{u 1}\left(t_{m}^{-}\right)<0$

The evolution of $V_{u 1}(t)$ is described by equation (A-2) in which $V_{u 0}(t)$ is replaced by $V_{u 1}(t)$ and $s$ is maximized over a constrained set $(s \geq \bar{s})$ beyond $t_{m}$. At $t_{m}, \dot{V}_{u 1}\left(t_{m}\right)=0$, so that

$$
r V_{u 1}\left(t_{m}\right)=z-c(\bar{s})+\lambda \bar{s}\left[V_{e}-V_{u 1}\left(t_{m}\right)\right]
$$

If we evaluate this expression at the suboptimal search intensity $\bar{s}$ at any $t<t_{m}$, the following inequality must be satisfied:

$$
r V_{u 1}(t)>z-c(\bar{s})+\lambda \bar{s}\left[V_{e}-V_{u 1}(t)\right]+\dot{V}_{u 1}(t)
$$

\footnotetext{
${ }^{39}$ Manning (2005) makes the same assumption. Since it allows us to reproduce the stylized facts, there is no need for a more complicated assumption.
} 
Subtracting equation (A-4) from (A-5) yields:

$$
(r+\lambda \bar{s})\left[V_{u 1}(t)-V_{u 1}\left(t_{m}\right)\right]>\dot{V}_{u 1}(t)
$$

We now prove by contradiction. Suppose that there exists some $d t$ such that, for any $t \in\left[t_{m}-\right.$ $\left.d t, t_{m}\right], \dot{V}_{u 1}(t) \geq 0$. Consequently, $V_{u 1}\left(t_{m}-d t\right) \leq V_{u 1}\left(t_{m}\right)$, but this contradicts the inequality in (A-6), since $\dot{V}_{u 1}(t) \geq 0$ by assumption. Therefore there must exist a $d t$ such that $\dot{V}_{u 1}(t)<0$ for any $t \in\left[t_{m}-d t, t_{m}\right]$. Taking the limit for $d t \rightarrow 0$ proves that $\dot{V}_{u 1}\left(t_{m}^{-}\right)<0$.

2. $\forall t<t_{m}: \dot{V}_{u 1}(t)<0$

Following a similar reasoning as above, for any $d t$ and $d \tau$, the following inequality must be satisfied:

$$
\left[r+\lambda s\left(t_{m}-d t\right)\right]\left[V_{u 1}\left(t_{m}-d t-d \tau\right)-V_{u 1}\left(t_{m}-d t\right)\right] \geq \dot{V}_{u 1}\left(t_{m}-d t-d \tau\right)-\dot{V}_{u 1}\left(t_{m}-d t\right)
$$

The reasoning is again by contradiction. Choose $d t$ such that $\dot{V}_{u 1}(t)<0$ for all $t \in\left[t_{m}-d t, t_{m}\right]$. Suppose that there exists some $d \tau$ such that, for any $t \in[t-d t-d \tau, t-d t], \dot{V}_{u 1}(t) \geq 0$. Consequently, $V_{u 1}\left(t_{m}-d t-d \tau\right) \leq V_{u 1}\left(t_{m}-d t\right)$, but this can only satisfy the inequality (A-7) if $\dot{V}_{u 1}\left(t_{m}-d t-d \tau\right)<0$, since $\dot{V}_{u 1}\left(t_{m}-d t\right)<0$. This contradicts our initial assumption. Therefore there must exist a $d \tau$ such that $\dot{V}_{u 1}(t)<0$ for any $t \in\left[t_{m}-d t-d \tau, t_{m}-d t\right]$. Repeating this argument proves the proposition.

To derive the evolution of $s_{1}(t)$ for $t \leq t_{m}$, we differentiate the first-order condition (A-3) with respect to $t$ :

$$
\forall t \leq t_{m}: \dot{s}_{1}(t)=-\frac{\lambda \dot{V}_{u 1}(t)}{c^{\prime \prime}\left[s_{1}(t)\right]}>0
$$

showing that job search effort must be increasing before $t_{m}$. Finally, since the monitoring just imposes a constraint on the unemployed claimant, it must be that $V_{u 0}(0)>V_{u 1}(0)$. Using the first-order condition (A-3), this implies that $s_{0}(0)<s_{1}(0)$, i.e. that the job search effort jumps upwards at the moment of notification.

\section{A-3 The impact of simultaneously counseling notified claimants}

The model in the previous section captures the stylized features of the monitoring scheme in Flanders. In Wallonia, however, the notification is immediately followed by counseling at the Regional Employment Office. In this section we consider the impact of this additional counseling on job search behavior.

For simplicity, we assume that counseling just increases the effectiveness of job-search: $\lambda_{2}>\lambda$. The first order condition of optimal job search is therefore given by

$$
\lambda_{2}\left[V_{e}-V_{u 2}(t)\right]=c^{\prime}\left[s_{2}(t)\right]
$$

Counseling increases the returns to job search, so that $s_{2}(t) \geq s_{1}(t)$ for all $t$. It will therefore also imply that the job search requirement imposed by the monitoring scheme will be binding for a smaller number of workers. The increasing profile in the transition rate to employment should therefore 
be observed for a smaller number of workers, unless participation in other training programs (not modeled) results in a steeper profile.

\section{A-4 The impact of announcing that both monitoring and counseling will take place at some future date}

In Brussels shortly after being notified of the future monitoring, the worker is convoked to a collective meeting in which he/she is informed about the workings of the UI scheme. At this meeting, one announces in addition that the claimants will be counseled individually shortly after the first monitoring interview has taken place. In this section, we demonstrate that this announcement may reverse the threat effect of monitoring. Intuitively, the argument goes as follows. In the previous section we have demonstrated that counseling increases the returns to job search and that the worker therefore voluntary intensifies job search. Consequently, the job search requirements will no longer be binding for a number of workers. If so, the prospect of counseling will dominate the threat of monitoring: the worker will be better off after $t_{m}$ then before. This will reduce his job search effort before $t_{m}$.

Consider a worker whose job search intensity, as a consequence of counseling, increases above the requirements imposed by the monitoring scheme: $s_{3}\left(t_{m}\right)>\bar{s}$. Denote the expected lifetime utility of this worker by $V_{u 3}(t)$. Following a similar argumentation to the one in Section 1, we can show that the job search effort should jump upwards at time $t_{m}$. To determine the evolution of $s(t)$ before $t_{m}$, we first prove the following proposition:

Proposition 2: $\forall t \leq t_{m}: \dot{V}_{u 3}(t)>0$

Proof:

Using the first-order conditions (A-3) and (A-9), for the job search intensity, respectively before and after $t_{m}$, one can derive a condition similar to the one defined in equation (A-7):

$$
\begin{array}{r}
r\left[V_{u 3}\left(t_{m}^{+}-d \tau\right)-V_{u 3}\left(t_{m}^{+}-d t-d \tau\right)\right] \geq\left[c^{\prime}\left[s_{3}\left(t_{m}^{+}-d \tau\right)\right]-c^{\prime}\left[s_{3}\left(t_{m}^{+}-d t-d \tau\right)\right]\right] s_{3}\left(t_{m}^{+}-d \tau\right) \\
+\dot{V}_{u 3}\left(t_{m}^{+}-d \tau\right)-\dot{V}_{u 3}\left(t_{m}^{+}-d t-d \tau\right)
\end{array}
$$

Consider first $d \tau=0$ and assume that $\dot{V}_{u 3}(t) \leq 0$ for all $t \in\left[t_{m}-d t, t_{m}\right]$. In this case the above inequality (A-10) cannot be satisfied, since then $V_{u 3}\left(t_{m}^{+}\right) \leq V_{u 3}\left(t_{m}^{+}-d t\right)$, but also $\dot{V}_{u 3}\left(t_{m}^{+}\right)=0$ and $c^{\prime}\left[s_{3}\left(t_{m}^{+}\right)\right]>c^{\prime}\left[t_{m}-d t\right]$, a contradiction. Consequently, there must exist some $d \tau>0$ such that $\dot{V}_{u 3}(t)>0$ for all $t \in\left[t_{m}-d \tau, t_{m}\right]$.

Assume now that there exists a $d t>0$ such that $\dot{V}_{u 3}(t) \leq 0$ for all $t \in\left[t_{m}-d t-d \tau, t_{m}-d \tau\right]$. This contradicts again the above inequality, since (a) it implies that $V_{u 3}\left(t_{m}^{+}-d \tau\right) \leq V_{u 3}\left(t_{m}^{+}-d t-d \tau\right)$, which in turn by (A-9) implies that $c^{\prime}\left[s_{3}\left(t_{m}^{+}-d \tau\right)\right] \geq c^{\prime}\left[s_{3}\left(t_{m}^{+}-d t-d \tau\right)\right.$ and (b) $\dot{V}_{u 3}(t-d \tau)>0$, so that (A-10) can only be satisfied if $\dot{V}_{u 3}\left(t_{m}-d t-d \tau\right)>0$, a contradiction. Repeating this argument proves that $\dot{V}_{u 3}(t)>0$ for $t<t_{m}$.

Inserting this in (A-8) in which we replace the sub-indices "1" to "3", it follows that the job-search intensity must decrease for all $t<t_{m}$. In addition, since the counseling increases the welfare of the 
Figure A-1: The Evolution of Job-Search Effort

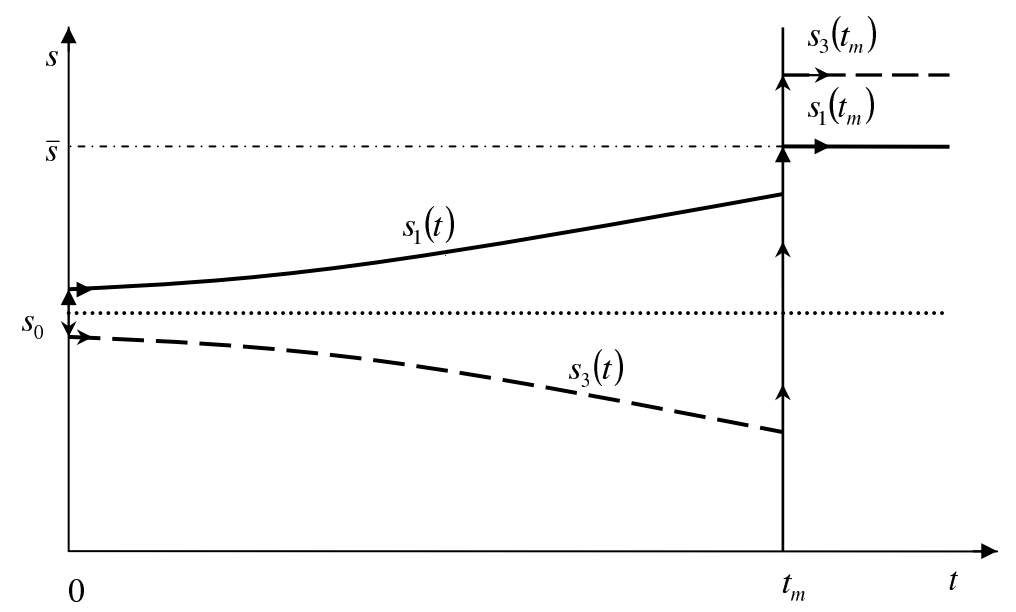

unemployed worker, $V_{u 3}(0)>V_{u 0}(0)$, it follows from (A-3), in which we replace the sub-index appropriately, that job search effort falls discontinuously at the moment at which the worker is informed that he will be counseled (and monitored) at time $t_{m}: s_{3}(0)<s_{0}(0)$. Consequently, the employment probability of this worker decreases relative to the pre-reform level until $t_{m}$, after which it will increase to a higher level. This profile will not be observed for all workers, however. All depends on the perceived quality of the the counseling relative to the stringency of the job search requirements. The latter can compensate or dominate the former, implying respectively no or a positive effect on the employment probability prior to $t_{m}$.

Figure A-1 summarizes the time-paths of the job-search effort $s(t)$ from the moment of dispatch of the notification letter $t=0$ to the moment $t=t_{m}$ of the monitoring (and possibly counseling) for the cases considered in this Appendix. Note that qualitatively the evolution of $s_{2}(t)$ corresponds to that of $s_{1}(t)$. 
Table A-1: Local Average Treatment Effects of the Predetermined Variables and of the Number of Individuals by Age Class ${ }^{\dagger}$

\begin{tabular}{|c|c|c|c|c|c|c|}
\hline \multirow[b]{2}{*}{ Variables } & \multicolumn{2}{|c|}{ Brussels } & \multicolumn{2}{|c|}{ Flanders } & \multicolumn{2}{|c|}{ Wallonia } \\
\hline & Coefficient & (s.e.) & Coefficient & (s.e.) & Coefficient & (s.e.) \\
\hline \# individuals by age-group ${ }^{\text {(a) }}$ & 2,061 & $(1.507)$ & 1,022 & $(1.707)$ & $-1,777$ & (1.746) \\
\hline \multicolumn{7}{|l|}{ Sex } \\
\hline men & -0.047 & $(0.054)$ & $-0.062^{*}$ & $(0.037)$ & 0.041 & $(0.036)$ \\
\hline women & 0.047 & $(0.047)$ & 0.061 & $(0.038)$ & -0.041 & $(0.036)$ \\
\hline \multicolumn{7}{|l|}{ Nationality } \\
\hline Belgian & 0.015 & $(0.050)$ & 0.003 & $(0.025)$ & -0.026 & $(0.032)$ \\
\hline EU15 (excluding Belgian) & -0.016 & $(0.037)$ & -0.001 & $(0.016)$ & 0.023 & $(0.026)$ \\
\hline Others & 0.001 & $(0.043)$ & -0.002 & $(0.022)$ & 0.003 & $(0.015)$ \\
\hline \multicolumn{7}{|l|}{ Schooling level } \\
\hline primary & -0.061 & $(0.037)$ & -0.037 & $(0.031)$ & 0.022 & $(0.038)$ \\
\hline lower secondary & 0.033 & $(0.044)$ & $0.082^{* *}$ & $(0.035)$ & 0.024 & $(0.033)$ \\
\hline upper secondary & -0.054 & $(0.055)$ & -0.012 & $(0.040)$ & -0.042 & $(0.041)$ \\
\hline higher education & 0.057 & $(0.045)$ & -0.035 & $(0.037)$ & -0.000 & $(0.032)$ \\
\hline other studies & 0.024 & $(0.050)$ & 0.002 & $(0.003)$ & -0.003 & $(0.020)$ \\
\hline \multicolumn{7}{|l|}{ Category } \\
\hline head of household & -0.052 & $(0.053)$ & 0.042 & $(0.035)$ & 0.043 & $(0.037)$ \\
\hline single & 0.020 & $(0.052)$ & -0.009 & $(0.033)$ & 0.035 & $(0.035)$ \\
\hline cohabitant & 0.032 & $(0.052)$ & -0.032 & $(0.040)$ & $-0.067^{*}$ & $(0.038)$ \\
\hline \multicolumn{7}{|l|}{ Type of entitlement } \\
\hline work experience & 0.060 & $(0.040)$ & $0.007^{(b)}$ & $(0.019)$ & 0.029 & $(0.033)$ \\
\hline school-leaver & -0.060 & $(0.039)$ & $-0.007^{(b)}$ & (0.019) & $-0.029^{(c)}$ & $(0.031)$ \\
\hline Participation in training & 0.001 & $(0.023)$ & 0.026 & $(0.024)$ & -0.031 & $(0.025)$ \\
\hline UI duration in months & -0.301 & $(0.728)$ & 0.622 & $(0.481)$ & -0.221 & $(0.500)$ \\
\hline Recent UI interruption & 0.021 & $(0.064)$ & -0.021 & $(0.037)$ & 0.026 & $(0.035)$ \\
\hline Unemployment rate by district & - & - & 0.092 & $(0.146)$ & -0.162 & $(0.428)$ \\
\hline Number of observations & \multicolumn{2}{|c|}{1346} & \multicolumn{2}{|c|}{2519} & \multicolumn{2}{|c|}{2413} \\
\hline
\end{tabular}

$\dagger$ Model with a linear polynomial in age, unless specified otherwise. To allow for specification error induced by the grouping of age in monthly intervals, we adjust the standard errors for clustering within these groups (Lee and Card, 2006).

(a) Age measured in months. This approximates McCrary's test on the continuity of the density of the running variable.

(b) $3^{r d}$ degree polynomial in age.

(c) $2^{\text {nd }}$ degree polynomial in age.

* Significant at the $10 \%$ level.

** Significant at the $5 \%$ level. 


\section{References}

Abbring, J. H., G. J. van den Berg, and J. C. van Ours (2005) 'The Effect of Unemployment Insurance Sanctions on the Transition Rate from Unemployment to Employment.' The Economic Journal 115(505), 602-630

Ashenfelter, O., D. Ashmore, and O. Deschênes (2005) ‘Do Unemployment Insurance Recipients Actively Seek Work? Evidence from Randomized Trials in Four U.S. States.' Journal of Econometrics 125(1-2), 53-75

Black, D. A., J. A. Smith, M.C. Berger, and B.J. Noel (2003) 'Is the Threat of Reemployment Services More Effective than the Services Themselves? Evidence from Random Assignment in the UI System.' American Economic Review 93, 1313-1327

Blundell, R., M. Costa Dias, C. Meghir, and J. Van Reenen (2004) 'Evaluating the Employment Impact of a Mandatory Job Search Program.' Journal of the European Economic Association $2,569-606$

Boone, J., P. Fredriksson, B. Holmlund, and J. van Ours (2001) 'Optimal Unemployment Insurance with Monitoring and Sanctions.' Discussion Paper 85, Tilburg: CentER , Tilburg University

Campbell, D. (1969) 'Reforms as Experiments.' American Psychologist XXIV, 409-429

Cockx, B., A. Defourny, M. Dejemeppe, and B. Van der Linden (2007) Le nouveau système de suivi des chômeurs (Louvain-la-Neuve)

Cockx, B., and J. Ries (2004) 'The Exhaustion of Unemployment Benefits in Belgium. Does it Enhance the Probability of Employment?' Discussion Paper No. 1177, Bonn: IZA

Crépon, B., M. Dejemeppe, and M. Gurgand (2006) 'Counselling the Unemployed: Does it Lower Unemployment Duration and Recurrence?' mimeo, Paris and Louvain-la-Neuve: CREST and Department of Economics, Université catholique de Louvain

Devine, T. (1988) 'Arrival versus Acceptance: The Source of Variation in Reemployment Rates Across Demographic Groups.' Working Paper, Pensylvania State University

Dolton, P., and D. O'Neill (1995) 'The Impact of Restart on Reservation Wages and Long Term Unemployment.' Oxford Bulletin of Economics and Statistics 57, 451-470

(1996) 'Unemployment Duration and the Restart Effect: Some Experimental Evidence.' The Economic Journal 106(435), 387-400

Forslund, A., and O. Nordström Skans (2006) 'Swedish Youth Labour Market Policies Revisited.' Working Paper 2006:6, Uppsala: IFAU 
Fredriksson, P., and B. Holmlund (2006) 'Improving Incentives in Unemployment Insurance: A Review of Recent Research.' Journal of Economic Surveys 20(3), 357-386

Geerdsen, L. P. (2006) 'Is there a Threat Effect of Labour Market Programmes? A Study of ALMP in the Danish UI System.' The Economic Journal 116, 738-750

Geerdsen, L. P., and A. Holm (2007) 'Duration of UI Periods and the Perceived Threat Effect from Labour Market Programmes.' forthcoming in Labour Economics

Gorter, C., and G.R.J. Kalb (1996) 'Estimating the Effect of Counseling and Monitoring the Unemployed Using a Job Search Model.' Journal of Human Resources 31, 590-610

Graversen, B. K., and J. C. van Ours (2006) 'How to Help Unemployed to Find Jobs Quickly: Experimental Evidence from a Mandatory Activation Program.' Discussion Paper No. 2504, Bonn: IZA

Hägglund, P. (2006) 'Are there Pre-Programme Effects of Swedish Active Labour Market Policies? Evidence from Three Randomised Experiments.' Working Paper 2006:2, Uppsala: IFAU

Hahn, J., P. Todd, and W. van der Klaauw (2001) 'Identification and Estimation of Treatment Effects by Regression Discontinuity Design.' Econometrica 63(3), 201-209

Klepinger, D. H., T.R. Johnson, and J.M. Joesch (2002) 'Effects of Unemployment Insurance Work Search Requirements: The Maryland Experiment.' Industrial and Labor Relations Review 56(1), 3-22

Klepinger, D. H., T.R. Johnson, J.M. Joesch, and J.M. Benus (1997) Evaluation of the Maryland Unemployment Insurance Work Search Demonstration (Seattle and Bethesda: Batelle Memorial Instiute and Abt Associates Inc.)

Kluve, J. (2006) 'The Effectiveness of European Active Labor Market Policy.' Discussion Paper No. 2018, Bonn: IZA.

Lee, D. S., and D. Card (2006) 'Regression Discontinuity Inference with Specification Error.' NBER Technical Working Paper No. 322, Cambridge: National Bureau of Economic Research

Lemieux, T., and K. Milligan (2006) 'Incentive Effects of Social Assistance: A Regression Discontinuity Approach.' Analytical Studies Branch Research Paper Series 11F0019MIE No. 280, Ottawa: Business and Labour Market Analysis, Statistics Canada

Leuven, E., and H. Oosterbeek (2004) 'Evaluating the Effect of Tax Deductions on Training.' Journal of Labor Economics 22(2), 461-488 
Manning, A. (2005) 'You Can't Always Get What You Want: The Impact of the UK Jobseeker's Allowance.' Discussion Paper No. 697, London: Center for Economic Performance, London School of Economics

Martin, J. P., and D. Grubb (2001) 'What Works and for Whom: A Review of OECD Countries' Experiences with Active Labour Market Policies.' Swedish Economic Policy Review $8(2), 9-56$

Massant, R. (2005) Werkgelegenheid en werkloosheid. Enquête naar de arbeidskrachten (Brussels: Algemene Directie Statistiek en Economische Informatie)

McCrary, J. (2007) 'Manipulation of the Running Variable in the Regression Discontinuity Design: A Density Test.' Technical Working Paper 334, Cambridge, MA: NBER, forthcoming Journal of Econometrics

Meyer, B. D. (1995) 'Lessons from the U.S. Unemployment Insurance Experiments.' Journal of Economic Literature 33, 91-131

Mortensen, D. (1986) 'Job Search and Labor Market Analysis.' In Handbook of Labor Economics, Vol. II, ed. O. Ashenfelter and R. Layard (Amsterdam: North-Holland) pp. 849-919

ONEM (2004) Bulletin mensuel Juin (Brussels: ONEM)

Porter, J.R. (2003) 'Estimation in the Regression Discontinuity Model.' Working Paper, Harvard Univertsity

Rosholm, M., and M. Svarer (2004) 'Estimating the Threat Effect of Active Labour Market Programmes.' Discussion Paper No. 1300, Bonn: IZA

RVA (2006a) Jaarverslag 2005 (Brussels: RVA) (2006b) Statistisch Jaarboek 2005 (Brussels: RVA)

van den Berg, G. J. (1990) 'Nonstationarity in Job Search Theory.' Review of Economic Studies $57(2), 255-277$

van den Berg, G. J., and B. van der Klaauw (2005) 'Job Search Monitoring and Sanctions.' Journal for Institutional Comparisons 3(2), 26-29

(2006) 'Counseling and Monitoring of Unemployed Workers: Theory and Evidence from a Controlled Social Experiment.' International Economic Review 47(3), 895-936

van der Klaauw, W. (2002) 'Estimating the Effect of Financial AId Offers on College Enrollment: A Regression-Discontinuity Approach.' International Economic Review 43(4), 12491287 
van Ours, J. C., and M. Vodopivec (2006) 'Shortening the Potential Duration of Unemployment Benefits Does not Reduce the Quality of Post-Unemployment Jobs: Evidence from a Natural Experiment.' Discussion Paper No. 2171, Bonn: IZA

Wolpin, K. (1987) 'Estimating a Structural Job Search Model: The Transition from School to Work.' Econometrica 55, 801-818

Wooldridge, J. M. (1997) 'On Two Stage Least Squares Estimation of the Average Treatment Effect in a Random Coefficient Model.' Economic Letters 56, 129-133 